\title{
PERFIL DA PRODUÇÃO CIENTÍFICA DOS DOCENTES EM UMA INSTITUIÇÃO FEDERAL DE ENSINO SUPERIOR NO BRASIL
}

FACULTY SCIENTIFIC PRODUCTION PROFILE IN A FEDERAL HIGHER EDUCATION INSTITUTION IN BRAZIL

\section{PERFIL DE LA PRODUCCIÓN CIENTÍFICA DE LOS DOCENTES EN UNA INSTITUCIÓN FEDERAL DE ENSENÃNZA SUPERIOR EN BRASIL}

\author{
CLÁUDIO MAFRA \\ Doutorado em Ciências Biológicas (Bioquímica) pela Universidade Federal do Rio Grande do Sul. \\ Professor do Programa de Pós-Graduação em Bioquímica Aplicada, Departamento de Bioquímica e \\ Biologia Molecular da Universidade Federal de Viçosa. Presidente da Sociedade Brasileira de \\ Biossegurança e Bioproteção \\ mafra@ufv.br \\ ORCID: 0000-0003-0101-4212
}




\title{
Resumo
}

Prática não usual nas universidades em todo o mundo, conhecer o perfil de sua produção acadêmica e científica pode ser útil para o estabelecimento de estratégias de desenvolvimento institucional e nacional. Neste contexto, foi delineado o perfil da pesquisa e produção científica do corpo docente de uma IFES, nacional e internacionalmente citada por sua excelência, reconhecida em estudo encomendado pela CAPES sobre a pesquisa científica brasileira, período $2011-2016$, como na $12^{\mathrm{a}}$ posição, quando considerado o número absoluto de seus produtos científicos indexados. Apesar desta posição de destaque quanto ao volume de sua produção científica, quando em comparação com congêneres nacionais, esta instituição apresentou baixos índices frente aos parâmetros qualitativos considerados no referido relatório. Nesse sentido, este estudo buscou entender o porquê desta disparidade. Assim, delineou-se o perfil da produção científica desta IFES avaliando-se títulos dos veículos nos quais tais publicações ocorreram; distribuição e concentração desta publicação por campi, centro de ciências e docente; perfil docente; participação docente em programas de pós-graduação; parâmetros quantitativos e qualitativos da produção científica e seu reconhecimento por seus pares; dentre outras variáveis. Ao final, discutindo-se quanto à adequação de avaliações desta natureza em instituições federais de Ensino Superior no Brasil, apresentando-se condutas que poderiam vir a incrementar a qualidade da produção científica, bem como racionalizar a utilização dos recursos públicos destinados a instituições de mesmo perfil, em um processo intrínseco, contínuo e necessário de gestão do conhecimento científico.

Palavras-chave: Análise da produtividade científica. Gestão do conhecimento. Parâmetros da produtividade acadêmica. Produtividade da pesquisa. Cientometria.

\begin{abstract}
An unusual practice in universities worldwide, knowing the profile of its academic and scientific production, can help establish institutional and national development strategies. In this context, the profile of research and scientific production of the faculty in a federal higher education institution, nationally and internationally cited for its excellence, recognized in a study commissioned by CAPES on Brazilian scientific research, the period 2011 - 2016, in the 12th position when considered the absolute number of its indexed scientific products was delineated. Despite this prominent position in terms of the volume of its scientific production, when compared to national counterparts, this institution had low rates compared to the qualitative parameters considered in that report. This study was carried out to understand this disparity. Thus, the profile of the scientific production of this federal higher education institution was outlined by evaluating the titles of the vehicles in which such publications occurred; distribution and concentration of this publication by campuses, science center, and professor; professor profile and participation in graduate programs; quantitative and qualitative parameters of scientific production and its recognition by peers; among other variables. In the end, discussing the adequacy of evaluations of this nature in federal institutions of higher education in Brazil, and presenting behaviors that could increase the quality of scientific production, as well as rationalize the use of public resources for institutions with the same profile, in an intrinsic, continuous and necessary scientific knowledge management process.
\end{abstract}

Keywords: Analysis of scientific productivity. Knowledge management. Academic productivity parameters. Research productivity. Scientometrics.

\section{Resumen}

Práctica inusual en universidades de todo el mundo, conocer el perfil de su producción académica y científica puede ser útil para el establecimiento de estrategias de desarrollo institucional y nacional. En este contexto, se delineó el perfil de la investigación y de la producción científica del cuerpo docente 
de una IFES, citada nacional e internacionalmente por su excelencia, reconocida en un estudio encargado por CAPES sobre la investigación científica brasileña, en el período 2011 - 2016, como en el puesto 12 cuando se considera el número absoluto de sus productos científicos indexados. A pesar de esta posición destacada en cuanto al volumen de su producción científica, en comparación con congéneres nacionales, esta institución presentó bajos índices en comparación con los parámetros cualitativos considerados en dicho informe. Buscando comprender la razón de esta disparidad, se llevó a cabo este estudio. Así, se delineó el perfil de la producción científica de esta IFES evaluando los títulos de los vehículos en los que se produjeron dichas publicaciones; distribución y concentración de esta publicación por campus, centro de ciencias y docentes; perfil docente; participación docente en programas de posgrado; parámetros cuantitativos y cualitativos de la producción científica y su reconocimiento por pares; entre otras variables. Al final, discutiendo la adecuación de evaluaciones de esta naturaleza en instituciones federales de enseñanza superior en Brasil, presentando comportamientos que podrían incrementar la calidad de la producción científica, así como racionalizar el uso de recursos públicos destinados a instituciones del mismo perfil, en un proceso de gestión del conocimiento científico intrínseco, continuo y necesario.

Palabras clave: Análisis de la investigación científica. Administración del conocimiento. Parámetros de la investigación académica. Productividad de la investigación. Cienciometria.

\section{INTRODUÇÃO}

Divulgado em janeiro de 2018, o relatório "Research in Brazil - A report for CAPES by Clarivate Analytics" ${ }^{1}$ foi realizado com a finalidade de conhecer o panorama da produção científica no Brasil. Nesta análise de alto nível do desempenho da pesquisa brasileira foram descritos avanços e identificados os parâmetros de produtividade, impacto, análise colaborativa e oportunidades, com base no banco de dados Web of Science, avaliando as publicações científicas com autores/co-autores nacionais no período 2011-2016.

Baseado no volume de produtos científicos indexados, foram listadas as 20 instituições brasileiras quantitativamente mais produtivas, tendo a Universidade Federal de Viçosa (UFV) se posicionado na $12^{\mathrm{a}}$ colocação quanto ao somatório de documentos científicos indexados com autorias/coautorias de pesquisadores brasileiros na referida base. Apesar de, à primeira vista, este ser um excelente resultado em valores absolutos, quando comparada no mesmo relatório com outras instituições de Ensino Superior quanto a parâmetros qualitativos como Impacto de citações com padronização por categoria, Porcentagem de documentos entre os $1 \%$ de maior impacto, Porcentagem de documentos

\footnotetext{
${ }^{1}$ Disponível em: https://www.Capes.gov.br/images/stories/download/diversos/17012018-CAPES-InCitesReportFinal.pdf. Acesso em: 30 jan. 2018.
} 
dentre os $10 \%$ de maior impacto, Porcentagem de documentos decorrentes de colaborações com a indústria e Porcentagem de colaborações internacionais, verifica-se que esta instituição se posiciona nas $19^{\mathrm{a}}, 15^{\mathrm{a}}, 20^{\mathrm{a}}, 17^{\mathrm{a}}$ e $18^{\mathrm{a}}$ colocações, respectivamente. No comparativo com demais IES localizadas no estado de Minas Gerais, observa-se, ainda, que seus valores se apresentaram abaixo das médias para todas as métricas qualitativas listadas.

Considerando tais dados, com o objetivo de compreender o porquê deste desempenho e suas possíveis causas, procurou-se delinear o perfil da produção científica do corpo docente desta IFES com o intuito de avaliar práticas e índices internos correntes referentes à pesquisa e à produção científica.

\section{METODOLOGIA}

Para caracterizar a estrutura de pesquisa e analisar a produção científica da UFV que deu origem aos resultados do estudo Research in Brazil, optou-se por trabalhar com o mesmo período coberto pelo referido relatório, qual seja, entre os anos 2011 - 2016, realizando-se a busca de todos os produtos científicos institucionais indexados, bem como de cada docente individualmente. Desta maneira, foi buscada tanto a produção científica indexada total da instituição, quanto autorias, coautorias e citações individuais acumuladas ao longo da carreira de cada docente. Para isto, considerando a estrutura das bases indexadas (CHOU, 2012; JOSHI, 2016), optou-se por trabalhar com o banco de dados Scopus, visto que este inclui um maior número de títulos indexados em todas as áreas das ciências. Também foram buscados, em diferentes bases institucionais de acesso público (Sistemas internos UFV e Plataforma Carlos Chagas/CNPq), os dados individuais de cada docente, optando-se por tratar todos os dados coletados em conjunto, sem identificação ou destaque individual.

Por questão metodológica, não foi realizada normalização dos dados brutos por área da ciência; estes apenas foram organizados conforme centro ou campus de lotação do docente. Também foram tabulados os requisitos para defesa de dissertações e teses, bem como para credenciamento e recredenciamento de docentes orientadores, conforme descrito nos Regimentos Internos de cada um dos programas de pós-graduação da instituição; e os valores de classificação no sistema Qualis e Fator de Impacto de cada veículo de divulgação científica em que as publicações científicas indexadas ocorreram. 
Cumpre ressaltar que, como a coleta de dados foi realizada sem a utilização de aplicativos especializados que buscam toda a informação em um mesmo momento, algumas pequenas variações individuais podem ter ocorrido visto que, pelo volume de dados, tais buscas foram desenvolvidas ao longo de oito meses - entre fevereiro a outubro de 2018.

\section{RESULTADOS E DISCUSSÃO}

\subsection{Perfil de lotação, regime de contratação e titulação dos docentes}

Em relação à distribuição e movimentação dos 1.303 membros do corpo docente da UFV no período de 2011 a 2016, 123 deles se encontravam lotados no Campus de Rio Paranaíba, 79 no Campus de Florestal e 1.101 no Campus Viçosa (Quadro 1).

Quadro 1- Perfil da distribuição dos docentes da UFV conforme campus e centro de lotação, período

\begin{tabular}{|c|c|c|c|c|}
\hline \multirow{2}{*}{ Campus } & $\begin{array}{c}\text { Centro de } \\
\text { Ciências }\end{array}$ & $\begin{array}{c}\text { Docentes na } \\
\text { ativa }\end{array}$ & $\begin{array}{c}\text { Docentes } \\
\text { aposentados }\end{array}$ & $\begin{array}{c}\text { Docentes } \\
\text { redistribuídos }\end{array}$ \\
\hline CRP $^{2}$ & - & 123 & 5 & 9 \\
\hline CAF & - & 79 & 8 & 5 \\
\hline \multirow{3}{*}{ CAV } & CCH & 206 & 23 & 13 \\
\cline { 2 - 5 } & CCE & 336 & 50 & 11 \\
\cline { 2 - 5 } & CCB & 295 & 38 & 10 \\
\cline { 2 - 5 } & CCA & 264 & 69 & 5 \\
\hline \multicolumn{2}{|c|}{ Totais } & $\mathbf{1 . 3 0 3}$ & $\mathbf{1 9 3}$ & $\mathbf{5 3}$ \\
\hline
\end{tabular}

Fonte: quadro elaborado pelo autor.

Verificou-se que 205 docentes lotados na UFV não possuíam o título de Doutor, estando 35 destes lotados no Campus Rio Paranaíba, 26 no Campus Florestal e 144 no Campus Viçosa. Daqueles lotados no Campus Viçosa, 56 estavam lotados no Centro de Ciências Humanas, Letras e Artes, 41 no Centro de Ciências Exatas, 44 no Centro de Ciências Biológicas e da Saúde e 3 no Centro de Ciências Agrárias. No caso do Centro de Ciências Biológicas e da Saúde, 39 dos 44 docentes não doutores estavam lotados no Departamento de Medicina e Enfermagem (Dados não demonstrados). Tal achado se deve, em parte, ao número

\footnotetext{
${ }^{2}$ Campus Rio Paranaíba; CAF- Campus Florestal; CAV- Campus Viçosa; CCH- Centro de Ciências Humanas, Letras e Artes; CCE- Centro de Ciências Exatas; CCB- Centro de Ciências Biológicas e da Saúde; CCA: Centro de Ciências Agrárias.
}

Revista Brasileira de Pós-graduação-RBPG, ISSN (on-line): 2358-2332.

Brasília, v.16, n. 36, jul./dez., 2020.

Estudos 
significante dos docentes deste departamento que não têm a atividade de docência como atividade profissional principal e/ou exclusiva.

Merece destaque que, do total de docentes não doutores da UFV no período avaliado $(n=205)$, apenas 35 foram contratados no formato de 40 horas, com todos os demais sendo contratados no regime de 40 horas com dedicação exclusiva. Restringindo-se a análise à data de admissão de docentes não doutores àqueles que ingressaram no ano de 2006 ou posterior, foram identificados 183 docentes. Destes, 90 foram contratados entre os anos de 2013 e 2016 (Dados não demonstrados). Essa análise foi realizada com o objetivo de estimar, pelo tempo passado desde a contratação, aqueles docentes com considerável dificuldade em obter titulação de doutor e, consequentemente, de habilitar-se para participar como docentes e orientadores em programas de pós-graduação, submeter projetos para financiamento de pesquisas e mesmo projetos com o intuito de orientação em nível de iniciação científica. Na prática, isso significa que o exercício de suas atividades acadêmicas está restrito ao ensino de graduação, extensão e administração, sem atuação em atividades de pesquisa e pós-graduação.

\subsection{Docentes bolsistas}

Dentre todos os docentes lotados na UFV, foram identificados 193 deles como bolsistas de Produtividade em Pesquisa ou Desenvolvimento Tecnológico do CNPq no primeiro semestre de 2018. Três destes estavam lotados no Campus Rio Paranaíba, um no Campus Florestal e 189 no Campus Viçosa, sendo estes últimos assim divididos: 4 no Centro de Ciências Humanas, Letras e Artes; 36 no Centro de Ciências Exatas; 61 no Centro de Ciências Biológicas e da Saúde; e 88 no Centro de Ciências Agrárias. Vale ressaltar que, dentre todos os bolsistas, apenas 8 na categoria Desenvolvimento Tecnológico (DT2) (Quadro 2).

Quadro 2 - Distribuição das bolsas CNPq de Produtividade em Pesquisa e Desenvolvimento Tecnológico concedidas a docentes lotados na UFV, $1^{\circ}$ semestre 2018

\begin{tabular}{|c|c|c|c|c|c|c|c|c|}
\hline \multirow[t]{3}{*}{ Campus } & \multirow{3}{*}{$\begin{array}{l}\text { Centro de } \\
\text { Ciências }\end{array}$} & \multicolumn{6}{|c|}{ Nível da bolsa CNPq } & \multirow[t]{3}{*}{ Totais } \\
\hline & & \multicolumn{2}{|c|}{ PQ1 } & \multicolumn{2}{|c|}{ PQ2 } & \multicolumn{2}{|c|}{ DT2 } & \\
\hline & & $\mathbf{M}$ & $\mathbf{F}$ & $\mathbf{M}$ & $\mathbf{F}$ & $\mathbf{M}$ & $\mathbf{F}$ & \\
\hline
\end{tabular}

Revista Brasileira de Pós-graduação-RBPG, ISSN (on-line): 2358-2332.

Brasília, v.16, n. 36, jul./dez., 2020.

Estudos 


\begin{tabular}{|c|c|c|c|c|c|c|c|c|}
\hline CRP $^{3}$ & - & 0 & 0 & 2 & 1 & 0 & 0 & $\mathbf{3}$ \\
\hline \multirow{2}{*}{ CAF } & - & 0 & 0 & 1 & 0 & 0 & 0 & $\mathbf{1}$ \\
\hline \multirow{3}{*}{ CAV } & $\mathbf{C C H}$ & 0 & 0 & 2 & 2 & 0 & 0 & $\mathbf{4}$ \\
\cline { 2 - 9 } & $\mathbf{C C E}$ & 15 & 4 & 13 & 3 & 1 & 0 & $\mathbf{3 6}$ \\
\cline { 2 - 9 } & $\mathbf{C C B}$ & 22 & 7 & 15 & 16 & 0 & 1 & $\mathbf{6 1}$ \\
\cline { 2 - 9 } & $\mathbf{C C A}$ & 57 & 5 & 16 & 4 & 4 & 2 & $\mathbf{8 8}$ \\
\hline \multicolumn{2}{|c|}{ Totais } & $\mathbf{9 4}$ & $\mathbf{1 6}$ & $\mathbf{4 9}$ & $\mathbf{2 6}$ & $\mathbf{5}$ & $\mathbf{3}$ & $\mathbf{1 9 3}$ \\
\hline
\end{tabular}

Fonte: quadro elaborado pelo autor.

Dentre todas as categorias de bolsistas $\mathrm{CNPq}$, verifica-se marcada desproporção quando considerada a distribuição entre docentes do sexo masculino e feminino, em especial no nível mais elevado destas bolsas (PQ1). Conforme diferentes autores (ABRAMO et al., 2015; MOSCHKOVICH; ALMEIDA, 2015; MOSS-RACUSIN et al., 2012), tal dado merece análise minuciosa para que se busque melhor compreender a representação de homens e mulheres na pesquisa científica, o impacto da maternidade e outras questões diretamente relacionadas à mulher, bem como a ocorrência de preconceitos e outros fatores diretos ou indiretos em ações tomadas, assumidas ou não, no ambiente acadêmico da instituição. Funcionalmente, também foram verificadas diferenças por gênero, com uma maior incidência de mulheres nas categorias de Professores Auxiliar, Assistentes, Adjunto e Associado, do que no topo de progressão da carreira, como Professores Titulares (Dados não demonstrados).

De acordo com Zainab (1999), em geral, o desempenho de um pesquisador depende de suas habilidades, mas também deriva de uma série de fatores ambientais e pessoais dependentes de gênero, com a discriminação surgindo nos estágios iniciais das relações professor-aluno. Moss-Racusin et al. (2012) mostram o viés sutil a favor dos alunos do sexo masculino que ocorre nas faculdades de ciências. Por seu turno, Abramo et al. (2015) compararam o desempenho da pesquisa para homens e mulheres em 99 campos de pesquisa na Itália, afirmando que os resultados obtidos são de interesse para a otimização de uma seleção eficiente, auxiliando na gestão e nas tomadas de decisões mais informadas na formulação de práticas de recrutamento, avanços na carreira e sistemas de incentivos.

\footnotetext{
${ }^{3}$ Campus Rio Paranaíba; CAF- Campus Florestal; CAV- Campus Viçosa; CCH- Centro de Ciências Humanas, Letras e Artes; CCE- Centro de Ciências Exatas; CCB- Centro de Ciências Biológicas e da Saúde; CCA: Centro de Ciências Agrárias; PQ1- Produtividade em Pesquisa - Nível 1; PQ2- Produtividade em pesquisa - Nível 2; DT2- Desenvolvimento Tecnológico - Nível 2, M- sexo masculino; F- sexo feminino.
} 
No contexto italiano, os autores supracitados observaram que a presença de mulheres no corpo docente seria limitada a 35,8\%, sendo não homogênea sua distribuição entre as áreas científicas, e particularmente baixa nas ciências exatas. A distribuição por gênero revelou maior incidência de mulheres no cargo de professor assistente do que entre os catedráticos, com diferenças de gênero perceptíveis entre os valores médios de desempenho (maiores para os homens), sem diferenças perceptíveis nos honorários daqueles docentes improdutivos.

Avaliando os currículos de pesquisadores brasileiros na base de dados Lattes, Perlin et al. (2017) observaram que os homens são mais produtivos que as mulheres, porém, apenas quando a quantidade de publicações é verificada, sendo o efeito verificado apenas em grupos individuais de áreas específicas. Analisando, de acordo com o gênero, as chances de acesso aos mais altos cargos de carreira e gestão docente do Brasil, a partir de estudo realizado na Universidade Estadual de Campinas (UNICAMP) por Moschkovich e Almeida (2015), foi evidenciado que: (i) as chances de avanço para o estrato mais elevado da carreira variam de acordo com a faculdade e/ou instituto; (ii) a velocidade de alcance do nível mais alto seria maior para as professoras; (iii) os cargos de gestão seriam relativamente mais abertos às professoras; (iv) a maior ou menor feminização da faculdade e/ou instituto não pareceu ter um efeito significativo sobre esses resultados. Nessa instituição, as docentes estariam mais concentradas em alguns cursos e seus colegas do sexo masculino mais dispersos nos diferentes cursos. Em conclusão, estes autores afirmaram que os resultados encontrados indicariam a necessidade de se examinar o modo como as mudanças organizacionais em geral e a implementação de políticas voltadas para o favorecimento das docentes, reforçando ou abolindo diferenças entre as carreiras de docentes de cada sexo.

Restringindo a análise pelo baixo quantitativo de artigos sobre a temática gênero, constatou-se que, dos 34 bolsistas de produtividade bolsistas do CNPq nas áreas de Medicina Oral e/ou Patologia Oral, de um total de 217 na área de Odontologia, 22 (64,7\%) eram do sexo masculino (ANDRADE et al., 2018).

Nesse estudo de metanálise, esses 34 pesquisadores bolsistas responderam por 5.449 artigos em periódicos científicos, com média de 160,26 artigos por pesquisador (variação de 67 a 323). Dos 5.449 artigos publicados por este grupo de pesquisadores, $3.176(58,28 \%)$ foram indexados na Web of Science (média de 93,41 artigos / pesquisador), com 3.035 $(55,67 \%)$ artigos indexados na Scopus (média de 89,23 artigos / pesquisador). O índice h 
mediano dos bolsistas desta subárea foi de 15,14 (ANDRADE et al., 2018). Na área de Engenharia de Produção, observou-se que bolsistas de produtividade em pesquisa geralmente apresentam alta produção científica e baixa produção técnica, enquanto bolsistas de desenvolvimento tecnológico apresentam baixa produção científica e alta produção técnica (PICININ et al., 2016). Em Medicina, Martelli et al. (2019) evidenciaram que os 542 pesquisadores médicos que receberam bolsa de produtividade do CNPq entre os anos de 2012 a 2014 publicaram durante suas carreiras acadêmicas 76.512 artigos, com média de 119 artigos por pesquisador (desvio padrão entre 77 a 174). Desses artigos, 36.584 (47,8\%) foram indexados na Web of Science, sendo citados 643.159 vezes, com média de 754 citações cada (variação de 356 a 1.447).

$\mathrm{Na}$ UFV, chama atenção a forte concentração das bolsas no Centro de Ciências Agrárias, seguido do Centro de Ciências Biológicas e da Saúde e do Centro de Ciências Exatas no período analisado. Tais dados merecem análise minuciosa, visto que tais bolsas significam o reconhecimento da excelência nas atividades científicas e tecnológicas desenvolvidas por docentes no Brasil. Como será observado em análises realizadas a seguir, a instituição possui considerável destaque por sua excelência na área científica de docentes lotados nos referidos centros de ciências e no campus Viçosa, com tradição e experiência reconhecidas em atividades de pesquisa e pós-graduação.

\subsection{Da área, veículo de divulgação e classificação do título do veículo de divulgação científica conforme Qualis e Fator de Impacto}

Dos 8.808 produtos científicos com autores e co-autores da UFV localizados, os artigos científicos, seguidos de resumos e artigos em conferências e revisões científicas publicadas em veículos indexados, representaram a grande maioria (93\%), se concentrando principalmente nas Ciências Agrárias e Biológicas (48,7\%), seguidas pelas Ciências Veterinárias (8,8\%), Bioquímica, Genética e Biologia Molecular (8,7\%), Medicina (6,8\%) e Ciências do Ambiente (5,2\%), totalizando 78,2\%. As demais áreas responderam por valores variando de 2,8 a $0,1 \%$, representando, no somatório, 21,8\% do total (Dados não demonstrados). 


\subsubsection{Perfil da produção científica classificada conforme Qualis e Fator de Impacto}

Avaliando a distribuição das produções científicas indexadas da UFV no período de 2011 a 2016, conforme a classificação Qualis 2013-2016 (considerando apenas o maior valor, independentemente da área), verificou-se que 55,12\% das 8.808 publicações científicas indexadas ocorreram distribuídas por um total de 1.301 títulos classificados como A; 38,04\% em veículos indexados classificados como B; e 0,19\% como C, com 6,64\% em veículos não classificados. No total, observa-se que $87,89 \%$ das publicações científicas indexadas ocorreram em periódicos com classificação Qualis igual ou superior a B1 (Quadro 3).

Quadro 3 - Produções científicas da UFV conforme classificação Qualis dos veículos de divulgação nos quais estas ocorreram, no período 2011 a 2016.

\begin{tabular}{|c|c|c|c|c|}
\hline $\begin{array}{c}\text { Classificação } \\
\text { Qualis }\end{array}$ & $\begin{array}{l}\text { Número de } \\
\text { artigos }\end{array}$ & $\begin{array}{c}\text { Número de } \\
\text { artigos por } \\
\text { extrato Qualis }\end{array}$ & $\begin{array}{l}\text { Percentual de } \\
\text { artigos }\end{array}$ & $\begin{array}{l}\text { Percentual de } \\
\text { artigos por } \\
\text { extrato Qualis }\end{array}$ \\
\hline A1 & 1.544 & \multirow[t]{2}{*}{4.855} & 17,53 & \multirow[t]{2}{*}{55,12} \\
\hline A2 & 3.311 & & 37,59 & \\
\hline B1 & 2.886 & \multirow{5}{*}{3.351} & 32,77 & \multirow{5}{*}{38,04} \\
\hline B2 & 411 & & 4,67 & \\
\hline B3 & 23 & & 0,26 & \\
\hline B4 & 25 & & 0,28 & \\
\hline B5 & 6 & & 0,07 & \\
\hline $\mathrm{C}$ & 17 & 17 & 0,19 & 0,19 \\
\hline $\mathrm{ND}^{4}$ & 585 & 585 & 6,64 & 6,64 \\
\hline
\end{tabular}

Fonte: quadro elaborado pelo autor.

No entanto, quando à avaliação qualitativa destes veículos, esta se deu considerando o Fator de Impacto dos mesmos e foi observado que apenas $1,79 \%$ das publicações se deram em veículos com valores entre 5,014 a 41,667; 15,41\% em veículos indexados com valores variando entre 2,002 e 4,950; 13,85\% em veículos entre 1,008 e 1,998; 22,42\% entre 0,502 e 1,0; e 41,16\% entre 0,0 e 0,5; com 5,36\% em títulos sem Fator de Impacto medido. Desta maneira, foram totalizados $68,94 \%$ das publicações em títulos com um Fator de Impacto igual ou inferior a 1,0 (Quadro 4).

${ }^{4}$ Não disponível. 
Quadro 4 - Produções científicas da UFV no período 2011 a 2016, conforme valor de Fator de Impacto dos veículos nos quais estas ocorreram.

\begin{tabular}{|c|c|c|}
\hline $\begin{array}{c}\text { Variação dos valores de } \\
\text { Fator de Impacto }\end{array}$ & $\begin{array}{c}\text { Produções científicas por faixa } \\
\text { de Fator de Impacto (n) }\end{array}$ & $\begin{array}{c}\text { Produções científicas por faixa } \\
\text { de Fator de Impacto (\%) }\end{array}$ \\
\hline $41,667-5,014$ & 158 & 1,79 \\
\hline $4,950-2,002$ & 1.358 & 15,41 \\
\hline $1.998-1,008$ & 1.220 & 13,85 \\
\hline $1,000-0,502$ & 1.975 & 22,42 \\
\hline $0,500-0,000$ & 3.625 & 41,16 \\
\hline ND $^{5}$ & 472 & 5,36 \\
\hline
\end{tabular}

Fonte: quadro elaborado pelo autor.

Observa-se que, quanto ao perfil das publicações indexadas considerando o Fator de Impacto atribuído a cada veículo, apenas $1,79 \%$ das publicações científicas da UFV ocorreram em títulos avaliados com valor igual ou superior a 5,0 (entre 5,014 e 41,667), tendo no outro extremo de qualidade cerca de $75 \%$ em revistas científicas avaliadas com Fator de Impacto igual ou inferior a 1,330.

De acordo com o Qualis, 87,89\% das publicações científicas indexadas ocorreram em periódicos com classificação igual ou superior a B1. De acordo com o Fator de Impacto, $68,94 \%$ das publicações ocorreram em títulos com um Fator de Impacto igual ou inferior a 1,0. Comparando os valores de Qualis e Fator de Impacto no intuito de compreender o porquê desta discrepância, verificou-se que, dentre aqueles títulos classificados como Qualis A1, o Fator de Impacto variou entre 0,028 a 41,667; naqueles classificados como A2, entre 0,061 e 5,24; como B, entre 0,0 e 3,707; como C, entre. Não definido e 1,74; e naqueles sem classificação Qualis, entre 0,162 e 6,173 (Quadro 5).

Quadro 5 - Perfil da produção científica da UFV no período 2011 a 2016, comparando-se classificação Qualis e Fator de Impacto por veículo indexado no qual ocorreram as publicações.

\begin{tabular}{|c|c|c|c|c|c|}
\hline $\begin{array}{c}\text { Classificaçã } \\
\text { o Qualis }\end{array}$ & $\begin{array}{l}\text { Número de } \\
\text { publicações } \\
\text { por extrato } \\
\text { Qualis }\end{array}$ & $\begin{array}{c}\text { Totais de } \\
\text { produções } \\
\text { científicas } \\
\text { por extrato } \\
\text { Qualis } \\
\end{array}$ & $\begin{array}{l}\text { Produções } \\
\text { científicas } \\
\text { por extrato } \\
\text { Qualis }(\%)\end{array}$ & $\begin{array}{c}\text { Variação dos } \\
\text { valores de Fator } \\
\text { de Impacto dos } \\
\text { títulos por } \\
\text { extrato Qualis }\end{array}$ & $\begin{array}{c}\text { Produções } \\
\text { científicas por } \\
\text { extrato do } \\
\text { Fator de } \\
\text { Impacto }(\%) \\
\end{array}$ \\
\hline A1 & 1.544 & \multirow{2}{*}{4.855} & 17,53 & $41,667-0,028$ & \multirow{2}{*}{55,12} \\
\hline $\mathbf{A 2}$ & 3.311 & & 37,59 & $5,24-0,061$ & \\
\hline B1 & 2.886 & \multirow{2}{*}{3.351} & 32,77 & $3,707-0,0$ & \multirow{2}{*}{38,05} \\
\hline B2 & 411 & & 4,67 & $3,694-0,137$ & \\
\hline
\end{tabular}

${ }^{5}$ Não definido

Revista Brasileira de Pós-graduação-RBPG, ISSN (on-line): 2358-2332.

Brasília, v.16, n. 36, jul./dez., 2020.

Estudos 


\begin{tabular}{|c|c|c|c|c|c|}
\hline B3 & 23 & & 0,26 & $1,472-0,0$ & \\
\hline B4 & 25 & & 0,28 & - & \\
\hline$\overline{B 5}$ & 6 & & 0,07 & - & \\
\hline $\mathbf{C}$ & 17 & 17 & 0,19 & $1,74-\mathrm{ND}$ & 0,19 \\
\hline $\mathrm{ND}^{6}$ & 585 & 585 & 6,64 & $6,173-0,162$ & 6,64 \\
\hline
\end{tabular}

Fonte: quadro elaborado pelo autor.

Em parte, podemos atribuir esta realidade como devida aos próprios programas de pós-graduação da instituição, os quais, em sua maioria, adotam como parâmetro qualitativo para a produção científica de seus docentes e discentes a classificação conforme o sistema Qualis.

Este procedimento não seria exclusivo desta instituição, pois, embora a CAPES afirme que o sistema Qualis não seja adequado para avaliações individuais, mas apenas para avaliação comparativa de programas na mesma área, comparando-o com outros entre comitês de áreas diferentes (BARATA, 2016), na prática, verifica-se exatamente o oposto. Assim, um volume significativo de programas de pós-graduação estabelece a classificação Qualis do veículo em que cada publicação ocorreu como requisito para permitir a defesa da tese e dissertação e/ou o credenciamento e recredenciamento de docentes e orientadores. Com isso reforçam a importância desta ferramenta para um propósito não originalmente planejado pela CAPES para a promoção e avaliação de programas de pós-graduação (BARATA, 2019).

Dentre os programas de pós-graduação da UFV, verificou-se que apenas dois, classificados como de nível 7 por suas respectivas áreas na CAPES, citam textualmente que utilizam valor de Fator de Impacto mínimo dos veículos de divulgação científica como requisito obrigatório para permitir a defesa de teses ou dissertações. Quase metade destes indicam em seus regimentos internos que, para a defesa, devem ser seguidos "os requisitos institucionais da UFV para programas de pós-graduação stricto sensu", apesar de no Regimento Geral dos Programas de Pós-Graduação Stricto Sensu da UFV não constar nenhuma referência a tal questão. Outros programas "simplificam" este aspecto, apresentando em seus regimentos internos como único requisito para defesa a exigência de publicação de "n" artigos em periódicos indexados. Em sua maioria, apresentando como exigência da questão qualitativa aqueles artigos classificados como B1 ou superior no Qualis da área em

${ }^{6}$ Não disponível

Revista Brasileira de Pós-graduação-RBPG, ISSN (on-line): 2358-2332.

Brasília, v.16, n. 36, jul./dez., 2020.

Estudos 
questão, ou simplesmente determinando que devem ser cumpridos os requisitos conforme documentos de cada área na CAPES.

Essa situação poderia ser considerada uma das causas diretas dos resultados qualitativos apresentados pela UFV no relatório produzido pela Clarivate Analytics para a CAPES, merecendo criteriosa análise e crítica interna. Quantitativamente de destaque, com valores críticos nos parâmetros qualitativos considerados no mesmo.

Pode-se ainda deduzir que está sendo formada uma geração de pesquisadores e cientistas que terão, em sua maioria, um parâmetro não adequado no que se refere à qualidade científica de suas publicações. Muito provavelmente, vindo a aplicar a seus futuros alunos e orientandos, a mesma (baixa) exigência de qualidade sob a qual foram formados, criando, assim, um círculo vicioso, impactando negativamente na qualidade da gestão do conhecimento científico e tecnológico. Uma prova desta cultura estar perigosamente inserida na conduta destes futuros cientistas e pesquisadores pode ser verificada em diferentes mídias e grupos digitais formados por discentes de pós-graduação no Brasil. Nestes, frequentemente encontramos, inclusive com efusivos parabéns aos que assim postam, manifestações de alunos de pós-graduação comunicando e comemorando a aceitação e/ou publicação de suas produções científicas tomando por base a pontuação Qualis dos periódicos científicos em que estas se deram, como se parâmetro de qualidade individual tal classificação fosse (Dados não demonstrados).

\subsubsection{Perfil dos veículos em que ocorreram as produções científicas indexadas da UFV}

Verificou-se que apenas 30 dos 1.303 títulos de periódicos indexados nos quais foram publicados os 8.808 produtos científicos da UFV no período 2011 a 2016, concentraram $3.493(39,7 \%)$ deste total, com seus respectivos Fatores de Impacto variando entre 0,137 e 0,92 para 29 destes 30 títulos, com apenas um apresentando Fator de Impacto igual a 3,54. Merece destaque que apenas 4 títulos dentre estes que concentraram significativa porção das produções científicas indexadas da UFV são periódicos não editados no Brasil, sendo sua quase totalidade nas Ciências Agrárias (Quadro 6). 
Quadro 6 - Lista dos 30 veículos de divulgação científica indexados na plataforma Scopus nos quais se concentraram aproximadamente 40\% de toda a produção científica da UFV no período 2011 a 2016, incluindo seus valores de Fator de Impacto e Qualis máximo, sem considerar a área conforme classificação CAPES

\begin{tabular}{|c|c|c|c|}
\hline Título do veículo de divulgação & $\begin{array}{c}\text { Número de } \\
\text { publicações com } \\
\text { autores/co-autores } \\
\text { da UFV } \\
\end{array}$ & $\begin{array}{c}\text { Fator de } \\
\text { Impacto } \\
\text { (2016) }\end{array}$ & 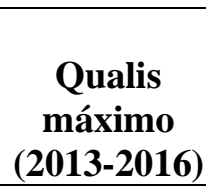 \\
\hline Revista Ceres & 420 & 0,335 & B1 \\
\hline Semina Ciências Agrárias & 280 & 0,309 & B1 \\
\hline Revista Árvore & 260 & 0,442 & $\mathrm{~A} 2$ \\
\hline Ciência Rural & 180 & 0,417 & $\mathrm{~A} 2$ \\
\hline Ciência Florestal & 180 & 0,33 & A2 \\
\hline Revista Brasileira De Zootecnia & 173 & 0,545 & $\mathrm{~A} 2$ \\
\hline Bioscience Journal & 164 & 0,267 & $\mathrm{~B} 2$ \\
\hline Pesquisa Agropecuária Brasileira & 133 & 0,542 & $\mathrm{~A} 2$ \\
\hline $\begin{array}{l}\text { Arquivo Brasileiro de Medicina Veterinária e } \\
\text { Zootecnia }\end{array}$ & 122 & 0,201 & $\mathrm{~A} 2$ \\
\hline Genetics And Molecular Research & 108 & 0,765 & $\mathrm{~A} 2$ \\
\hline Revista Brasileira De Ciência Do Solo & 105 & 0,609 & $\mathrm{~A} 2$ \\
\hline Scientia Forestalis Forest Sciences & 104 & 0,357 & B1 \\
\hline Cerne & 102 & 0,331 & $\mathrm{~A} 2$ \\
\hline Revista Brasileira de Ciências Agrárias & 92 & 0,26 & B1 \\
\hline Revista Caatinga & 89 & 0,267 & $\mathrm{~A} 2$ \\
\hline Plos One & 85 & 3,54 & A1 \\
\hline Tropical Plant Pathology & 80 & 0,81 & $\mathrm{~A} 2$ \\
\hline Planta Daninha & 77 & 0,461 & B1 \\
\hline Florida Entomologist & 77 & 0,964 & $\mathrm{~A} 2$ \\
\hline Revista Brasileira de Saúde e Produção Animal & 72 & 0,137 & $\mathrm{~B} 2$ \\
\hline Acta Horticulturae & 67 & 0,17 & B1 \\
\hline Acta Scientiarum Agronomy & 67 & 0,558 & A2 \\
\hline Revista Ciência Agronômica & 61 & 0,516 & B1 \\
\hline Coffee Science & 60 & 0,25 & B1 \\
\hline Zootaxa & 59 & 0,972 & B1 \\
\hline Engenharia Agrícola & 59 & 0,353 & $\mathrm{~A} 2$ \\
\hline Bragantia & 57 & 0,709 & B1 \\
\hline Horticultura Brasileira & 56 & 0,335 & B1 \\
\hline Revista Brasileira de Fruticultura & 52 & 0,477 & $\mathrm{~B} 1$ \\
\hline Crop Breeding and Applied Biotechnology & 52 & 0,701 & $\mathrm{~A} 2$ \\
\hline
\end{tabular}

Fonte: quadro elaborado pelo autor.

Dentre os títulos que publicaram os produtos científicos indexados contando com a participação de docentes da UFV como autores/co-autores, chama atenção que em apenas um destes veículos, a Revista Ceres, se concentrou 420 (4,77\%) de todas as 8.808 publicações indexadas no período de 2011 a 2016. Apenas este título, com um fator de impacto de 0,39, tendo Qualis B1 máximo (sem considerar a área), junto a três outros títulos, quais sejam: 
Revista Árvore, Revista Brasileira de Zootecnia e Planta Daninha, concentraram 12,9\% de toda a produção científica da UFV, merecendo ser citado que todos estes, sem exceção, são veículos apoiados ou com seu corpo editorial localizado na instituição. Com Qualis máximo de B1, A2, A2 e B1, nessa ordem, estes títulos apresentam valores referentes a Fator de Impacto de 0,$39 ; 0,531 ; 0,364 ;$ e 0,298 , respectivamente. Também se verificou que, com relação aos títulos apoiados pela UFV ou aqueles que possuem corpo editorial majoritariamente localizado na instituição $(n=16)$, doze não possuíam Fator de Impacto, com apenas três apresentando qualificação Qualis (Dados não demonstrados).

Essa característica institucional não estaria de acordo com o recomendado por Santos e Rabelo (2017). Esses autores afirmaram que, de maneira geral, os indicadores qualitativos significam, nacional e internacionalmente, a seriedade, visibilidade, qualidade e confiabilidade dos periódicos científicos. Estes, contribuindo para uma maior visibilidade da produção científica dos países, tendo por princípio, de maneira incontestável, a indexação destes veículos em grandes bancos de dados científicos regionais e mundiais, como SciELO, Scopus e Medline, dentre outros.

Silaghi-Dumitrescu e Sabau (2014) demonstraram que aproximadamente 10\% das publicações da Babes-Bolyai University, como entre as melhores das universidades romenas tendo química, física, religião, geologia, história, psicologia, matemática, ciência dos materiais como seus pontos fortes, assim como ecologia, bioquímica e biologia molecular ocorreu em periódicos próprios (quase metade deles), em um total de $25 \%$ em periódicos romenos. Para efeito de comparação, em todo o país 35\% dos artigos romenos foram publicados em revistas romenas. Finalizando, estes autores concluem como sendo esta prática tão improdutiva quanto a projetar a pesquisa local de encontro às principais correntes internacionais de conhecimento científico.

\subsection{Das autorias e coautorias}

Considerando a produção científica indexada do corpo docente da UFV no banco de dados Scopus, período 2011 a 2016, 10 docentes (0,77\%) foram identificados como extremamente produtivos, concentrando $11,38 \%$ de todas as autorias e coautorias da instituição. Ampliando a escala, observa-se que 30 docentes responderam por $23,4 \%$ das 
autorias e coautorias; 100 destes por 46,53\%; e 500 por 94,24\%, com 803 docentes respondendo pelas 5,76\% restantes (Quadro 7).

Quadro 7 - Somatório das produções científicas indexadas de docentes da UFV na plataforma Scopus, período 2011 a 2016.

\begin{tabular}{|c|c|c|c|}
\hline $\begin{array}{c}\text { Extrato docente } \\
\text { acumulado (n) }\end{array}$ & Acumulado (\%) & $\begin{array}{c}\text { Somatório acumulado } \\
\text { de autorias e } \\
\text { coautorias por } \\
\text { extrato docente }\end{array}$ & Acumulado (\%) \\
\hline $\mathbf{1 0}$ & 0,77 & 3.483 & 11,38 \\
\hline $\mathbf{2 0}$ & 1,54 & 5.545 & 18,12 \\
\hline $\mathbf{3 0}$ & 2,3 & 7.163 & 23,4 \\
\hline $\mathbf{5 0}$ & 3,84 & 9.628 & 31,45 \\
\hline $\mathbf{1 0 0}$ & 7,69 & 14.365 & 46,93 \\
\hline $\mathbf{2 5 0}$ & 19,22 & 22.828 & 74,58 \\
\hline $\mathbf{5 0 0}$ & 38,44 & 28.846 & 94,24 \\
\hline $\mathbf{1 3 0 1}$ & 100 & 30.609 & 100 \\
\hline
\end{tabular}

Fonte: quadro elaborado pelo autor.

Tais dados são dignos de cuidadosa análise, visto pouco mais de $1 / 3$ do total de docentes $(38,37 \%)$ ter respondido por quase a totalidade da produção científica da mesma $(94,24 \%)$.

Expandindo-se a avaliação da produção científica, considerando até o ano de 2017, foi verificado que 665 docentes $(51,11 \%)$ possuíam cinco ou menos artigos indexados ao longo de toda sua carreira acadêmica, com sete docentes $(0,54 \%)$ no extremo oposto apresentando entre 250 e 546 produtos indexados, cada um. Entre os extremos de altíssima e baixa ou inexistente produção científica, 168 docentes $(12,91 \%)$ possuíam entre 11 a 25 artigos indexados; $155(11,91 \%)$ entre 26 a 50; $132(10,15 \%)$ entre 51 a 100; e $58(4,46 \%)$ entre 101 a 250. Também chamou atenção o fato da não identificação de produção científica indexada ao longo de toda vida acadêmica para 432 docentes $(33,2 \%)$ e de 233 outros docentes tendo publicado entre 1 a 5 produtos científicos indexados (Quadro 8).

Quadro 8 - Perfil da distribuição da produção científica indexada de docentes da UFV na base Scopus ao longo de toda a vida acadêmica até o ano de 2017.

\begin{tabular}{|c|c|c|}
\hline $\begin{array}{c}\text { Produtos científicos indexados } \\
\text { (n) }\end{array}$ & Docentes (n) & Docentes (\%) \\
\hline 0 & 432 & 33,2 \\
\hline 1 a 5 & 233 & 17,91 \\
\hline 6 a 10 & 116 & 8,92 \\
\hline 11 a 25 & 168 & 12,91 \\
\hline
\end{tabular}

Revista Brasileira de Pós-graduação-RBPG, ISSN (on-line): 2358-2332.

Brasília, v.16, n. 36, jul./dez., 2020.

Estudos 


\begin{tabular}{|c|c|c|}
\hline $\begin{array}{c}\text { Produtos científicos indexados } \\
\text { (n) }\end{array}$ & Docentes (n) & Docentes (\%) \\
\hline 26 a 50 & 155 & 11,91 \\
\hline 51 a 100 & 132 & 10,15 \\
\hline 101 a 250 & 58 & 4,46 \\
\hline 250 a 546 & 7 & 0,54 \\
\hline
\end{tabular}

Fonte: quadro elaborado pelo autor.

Raro e semelhante estudo conduzido em nosso País, realizado na Universidade Federal de Goiás, mostrou que as publicações científicas de 1.487 docentes daquela instituição, no período de 2011 a 2013, variaram individualmente entre zero a 63. Dentre os artigos publicados, pontuados tomando a classificação Qualis como padrão de qualidade, foram identificados 989 produtos em periódicos $\mathrm{A} 1$, totalizando $18,7 \%$ do total, variando entre 0 a 32 por pesquisador. Neste estudo foi verificado, ainda, que $30 \%$ dos pesquisadores do corpo docente da referida instituição não publicaram nenhum artigo no período avaliado, estando as publicações identificadas concentradas em poucos membros do corpo docente, os quais publicaram muitos trabalhos, enquanto a maioria dos membros deste mesmo corpo docente pouco ou nada publicou. Segundo os autores de referido estudo, para aumentar o conhecimento, seria importante para a universidade ter como estratégia a contratação de jovens doutores produtivos, que aprenderam a publicar ou se envolveram em grupos de pesquisa com tal perfil. Desta maneira, focando no aumento da qualidade e quantidade da produção da pesquisa da instituição, não se superestimando o componente docência no processo de seleção de candidatos (DINIZ-FILHO et al., 2016).

\subsection{Das colaborações institucionais e internacionais}

Apesar de coautores nas produções indexadas dos docentes da UFV indicarem colaborações científicas destes com pesquisadores oriundos de 97 países, verificou-se que a grande maioria foi representada por parcerias com coautores brasileiros (80,6\%). Entre os países, verificou-se a maioria das coautorias concentrada nos EUA $(4,1 \%)$, Espanha $(1,4 \%)$, Alemanha (1,3\%), Reino Unido (1,2\%), França (0,9\%), Holanda, Austrália, Colômbia e Portugal (0,7\% cada) e Canadá $(0,6 \%)$. Refinando a análise no intuito de identificar a filiação institucional desses coautores, verificou-se que apenas 14 das 100 instituições que mais concentraram as produções indexadas com autores/coautores da UFV encontram-se 
localizadas no exterior, com a primeira destas aparecendo na $50^{\mathrm{a}}$ posição (Dados não demonstrados).

Nesse sentido, trabalhar associando políticas e oportunidades externas, com governança e estratégias internas, reconhecendo e abordando as particularidades das diferentes áreas das ciências desenvolvidas, posta-se como essencial para o crescimento nas áreas com expertise e infraestrutura instalada, bem como para a criação e desenvolvimento naquelas áreas que ainda não apresentam qualidade no nível de excelência estabelecido. Nessa linha, diversos programas de pós-graduação da UFV demandam forte apoio, em especial, aqueles classificados na CAPES de nível 3 a 5, os quais precisam melhorar sua qualidade e expandir suas atividades. Nisto, sem descuidar daqueles programas de nível 5, os quais, por serem de mérito nacional, mas sob forte pressão competitiva com outras congéneres nas respetivas áreas do conhecimento, necessitam suporte tanto para manter tal classificação, quanto para melhorar este índice.

Assim, conforme afirmado por Vasconcelos et al. (2012), a colaboração científica também torna a pesquisa mais eficiente por meio do compartilhamento de conhecimentos, instalações e materiais, especialmente para pesquisas complexas, que exigem infraestrutura, manutenção e insumos muito caros para serem gerenciados por uma única instituição ou país. Consequentemente, a cooperação internacional deve ser sempre o padrão em todos os níveis de pesquisa, desde grupos individuais a países. Esses autores argumentam que muitas questões de pesquisa são simplesmente grandes demais para serem abordadas por um único laboratório e requerem cooperação interdisciplinar e transfronteiriça. Esta deve ser uma estratégia a ser continuamente perseguida e apoiada.

\subsection{Do número de citações}

Verificou-se que apenas dez docentes no total de $1.303(0,77 \%)$ receberam 36.235 $(14,43 \%)$ de todas as 251.119 citações relacionadas à UFV até o ano de 2017, limite estipulado para a pesquisa deste dado. Trinta docentes receberam 30,03\% das citações; 100 receberam 57,92\%; e 500 receberam $97,76 \%$. Vale ressaltar que a grande maioria dos professores apresentou pouca ou nenhuma importância ou reconhecimento científico junto a seus pares nacionais ou internacionais, com 803 destes concentrando apenas 2,24\% do total de citações recebidas pela UFV (Dados não demonstrados). 
Avaliando-se individualmente cada docente, desconsiderando-se autocitações, foi verificado que pouco mais que metade destes $(50,57 \%)$ foi citada 25 vezes ou mais durante toda sua vida acadêmica, com alarmantes $35,16 \%(n=493)$ nunca citados. Verificou-se, ainda, que 60 docentes receberam entre 1.000 e 5.435 citações, dentre estes sendo nove com mais de 2.500 citações (Dados não demonstrados).

Apesar de preocupantes, estes dados devem ser tratados com relativo cuidado, pois, como destacado por Coural e Willcox (2003), alguns tipos de artigo podem registrar uma alta taxa de citações em um curto período, enquanto outros podem levar anos para serem reconhecidos, sem esquecer que as áreas de conhecimento têm dinâmicas diferentes. Tal discrepância entre a citação de artigos de diferentes áreas da ciência também é discutida por outros autores (ANTUNES, 2015; GÈNOVA et al., 2016; PICINI et al., 2016; SILAGHIDUMITRESCU; SABAU, 2014, ZAINAB, 1999). Para aprofundar nesta avaliação, evitandose injustiças quanto às diferentes áreas, é importante se realizar a análise destes dados normalizando-os conforme área e subárea.

Mesmo assim, dados indicando docentes sem nenhuma citação ao longo de toda sua carreira profissional são merecedores de análise, crítica e ação profundas e imediatas. Situação alertada por Kamdem et al. (2019), em estudo no qual as citações são incluídas entre os parâmetros que melhor refletem a qualidade de um trabalho, tal variável qualitativa não é considerada com a frequência devida na avaliação de pesquisadores brasileiros. De acordo com estes autores, a quantidade de docentes não citados merece análise profunda, podendo estar diretamente relacionada com falhas nas estratégias institucionais para contratação, recomposição, qualificação, permissão para períodos sabáticos (pós-doutorado) e para a inclusão docente na pesquisa e pós-graduação, dentre outras diretrizes e práticas de gestão institucionais. Com relação aos sabáticos, Diniz-Filho et al. (2016) afirmam que sabáticos para docentes com baixa produção científica pode ser uma maneira ineficiente se o intuito for melhorar a produção científica na instituição, devendo ser reavaliada.

Sem dúvida, estas são questões muito importantes a serem discutidas e estabelecidas, em especial considerando que se tratam de docentes do Ensino Superior lotados em uma instituição pública federal, e que deveriam, por lei, praticar a indissociabilidade entre ensino, pesquisa e extensão. 


\subsection{Perfil dos docentes quanto ao índice $h$}

Avaliando-se o índice h individual de cada docente da UFV obtido na base Scopus, foram observados valores variando entre zero a 44, com a seguinte distribuição por diferentes extratos: 312 docentes apresentando índice h igual a zero; 516 entre 1 a 3; 243 entre 5 a 9; 149 entre 10 a 14; 63 entre 15 a 19; 26 entre 20 a 29; e finalmente três apresentando, respectivamente, 30, 31 e 44. Para todos estes foram desconsideradas autocitações (Dados não demonstrados).

Avaliando-se a distribuição do índice h entre os docentes em suas diferentes áreas, tomando como referência para isto o programa de pós-graduação ao qual está associado, foi verificada uma grande dispersão destes valores em praticamente todos os programas. No entanto, em um menor número, foi observada também a inexistência de docentes com valores de índice $\mathrm{h}$ igual a zero ou muito baixos naqueles programas de melhor avaliação pela CAPES. Em especial naqueles avaliados como de nível 6 ou 7 (Quadro 9).

Quadro 9 - Variação do índice h dentre os docentes de cada programa de pós-graduação da UFV.

\begin{tabular}{|c|c|c|c|}
\hline Campus & Centro & Programa de Pós-Graduação & Variação Índice $h$ \\
\hline CAF & - & Manejo e Conservacão & 3 a 10 \\
\hline \multirow{24}{*}{ CAV } & \multirow[t]{9}{*}{ CCA } & Agroecologia & 13 \\
\hline & & Ciência florestal & 2 a 23 \\
\hline & & Engenharia agrícola & 0 a 12 \\
\hline & & Extensão rural & 0 a 2 \\
\hline & & Fitopatologia & 0 a 22 \\
\hline & & Fitotecnia & 0 a 20 \\
\hline & & Meteorologia aplicada & 7 a 31 \\
\hline & & Solos & 2 a 22 \\
\hline & & Zootecnia & 0 a 28 \\
\hline & \multirow[t]{14}{*}{ CCB } & Biologia Animal & 0 a 12 \\
\hline & & Biologia celular e estrutural & 2 a 19 \\
\hline & & Bioquímica aplicada & 0 a 24 \\
\hline & & Botânica & 0 a13 \\
\hline & & Ciências da nutrição & 4 a 22 \\
\hline & & Ciências da saúde & 0 a 8 \\
\hline & & Defesa Sanitária Vegetal & 3 \\
\hline & & Ecologia & 3 a 18 \\
\hline & & Educação Física & 4 a 14 \\
\hline & & Entomologia & 11 a 30 \\
\hline & & Fisiologia Vegetal & 6 a 44 \\
\hline & & Genética e Melhoramento & 10 a 22 \\
\hline & & Medicina Veterinária & 2 a 15 \\
\hline & & Microbiologia aplicada & 6 a 17 \\
\hline & CCE & Agroquímica & 0 a 18 \\
\hline
\end{tabular}

Revista Brasileira de Pós-graduação-RBPG, ISSN (on-line): 2358-2332.

Brasília, v.16, n. 36, jul./dez., 2020.

Estudos 


\begin{tabular}{|c|c|c|c|}
\hline Campus & Centro & Programa de Pós-Graduação & Variação Índice h \\
\hline & & Arquitetura e Urbanismo & 0 a 3 \\
\hline & & Ciência da Computação & 1 a 9 \\
\hline & & Ciência e tecnologia de alimentos & 0 a 24 \\
\hline & & Economia & 0 a 2 \\
\hline & & Economia aplicada & 0 a 5 \\
\hline & & Engenharia civil & 0 a 10 \\
\hline & & Engenharia química & 0 a 5 \\
\hline & & Ensino de física & 0 a 15 \\
\hline & & Estatística & 0 a 16 \\
\hline & & Física & 0 a 16 \\
\hline & & Matemática & 0 a 8 \\
\hline & & Matemática Rede & 0 \\
\hline & & Multicentro em química & 0 a 13 \\
\hline & \multirow[t]{6}{*}{$\mathbf{C C H}$} & Administração & 0 a 5 \\
\hline & & Administração Pública & 0 a 1 \\
\hline & & Economia doméstica & 0 a 2 \\
\hline & & Educação & 0 a 1 \\
\hline & & Letras & 0 a 3 \\
\hline & & Patrimônio cultural & 0 a 4 \\
\hline $\mathbf{C R P}^{7}$ & - & Agronomia Produção Vegetal & 0 a 10 \\
\hline
\end{tabular}

Fonte: quadro elaborado pelo autor.

Analisando o desempenho individual de cada professor, em um estudo semelhante conduzido na Babes-Bolyai University, Romênia, Silaghi-Dumitrescu e Sabau (2014) destacam pontos fortes e fracos de uma série de universidades internacionais líderes, referenciando dados nacionais de vários países. Foi observado que a porcentagem de pesquisadores com atividade razoavelmente alta (pelo menos uma publicação indexada por ano) foi relativamente baixa ( 10\%), com a porcentagem em uma posição competitiva internacionalmente elevada (com base em contagens de citações, número de publicações, livros indexados em bibliotecas internacionais) sendo apenas $\sim 2 \%$. Analisando o índice $\mathrm{h}$ individual do corpo docente desta instituição de Ensino Superior, foram identificados os 24 pesquisadores mais produtivos daquela instituição, com um valor médio de 14, sendo o maior de 25. Esses autores citaram que, em comparação com a University of Georgia, nos EUA, a média seria de 25, com valores atuais variando de 10 a 66 no Departamento de Química daquela instituição. Institucionalmente, $\mathrm{o}$ índice $\mathrm{h}$ da Babes-Bolyai University, com aproximadamente 1.500 professores, seria de 57.

\footnotetext{
${ }^{7}$ Campus Rio Paranaíba; CAF- Campus Florestal; CAV- Campus Viçosa; CCH- Centro de Ciências Humanas, Letras e Artes; CCE- Centro de Ciências Exatas; CCB- Centro de Ciências Biológicas e da Saúde; CCA: Centro de Ciências Agrárias.
}

Revista Brasileira de Pós-graduação-RBPG, ISSN (on-line): 2358-2332.

Brasília, v.16, n. 36, jul./dez., 2020.

Estudos 
Reconhecida como uma das métricas qualitativas para avaliação da produção docente e mesmo de instituições, o índice h considera a importância das publicações de um autor, ou de autores que têm por afiliação uma determinada instituição, tomando por base a frequência de citações que obtêm ao longo de sua carreira acadêmica (HIRSCH, 2005), sendo, no entanto, pouco considerada em nosso país para avaliação. Estudos com esse tipo de análise, listando as instituições brasileiras pelo índice h, até o momento não foram publicados. Com outros parâmetros, esse tipo de estudo poderia ser usado para apoiar a concepção de planos estratégicos institucionais e nacionais.

De acordo com Antunes (2015), dentre os vários índices para avaliar a importância científica, o número de citações é um dos mais utilizados, sendo o índice $\mathrm{h}$ atualmente considerado o mais adequado, com mínimas desvantagens.

Como discorre, influenciado por fatores sociológicos e estatísticos, o índice h tem sido aplicado para medir a produtividade e o impacto de grupos de pesquisa, universidades, periódicos científicos e até mesmo nações. Como variáveis sociológicas que influenciam seu cálculo, há a área temática da revista, o tipo de revista e a média de autores por artigo (que varia por tema). Assim, os valores estatísticos incluem o tamanho do periódico (número de artigos / ano) e o período de citações. Em relação ao índice h, pode-se afirmar que suas principais vantagens são: (i) facilmente obtido por qualquer pessoa, sendo de fácil entendimento; (ii) pode caracterizar a produção científica de um pesquisador de forma objetiva, principalmente em áreas onde existe uma cultura consolidada em periódicos referenciados, pode ser útil para promoções, alocação de recursos e alocação de prêmios; (iii) combina a quantidade e o impacto da pesquisa em um único indicador; (iv) apresenta desempenho superior a outros indicadores individuais, como fator de impacto, número de artigos, número de citações, citações por artigo e número de artigos muito citados, para avaliar a produtividade científica do pesquisador.

Dentre as principais desvantagens do índice h, estão: (i) não permite a comparação simples entre pesquisadores de áreas diferentes, pois o volume de citações varia de acordo com a área e o porte de cada comunidade de pesquisa; (ii) pode ser manipulado por meio de autocitações; (iii) atribui aos livros o mesmo peso dos artigos originais, dificultando a comparação de pesquisadores de áreas onde existe uma cultura de publicação de resultados de pesquisas em livros, como as humanidades; (iv) não considera o contexto da citação, não 
distinguindo entre um artigo de pesquisador ou pequeno grupo e um artigo com centenas de autores cuja participação individual é difícil de avaliar; (v) o impacto de uma publicação não é medido apenas por citações, mas também por muitas outras coisas, como sua contribuição para inovações tecnológicas ou para a formulação de políticas públicas.

Por estes motivos, considerando o número de citações, bem como o índice h, suas possibilidades e limitações, ressalta-se ao longo de todo este estudo a necessidade de serem realizados estudos normalizando os dados de cada área e subárea específica, suas particularidades e características.

\subsection{Participação docente nos editais internos de Iniciação Científica}

Ao avaliar a atividade docente da UFV tomando por base a participação em editais institucionais referentes a bolsas de Iniciação Científica (IC), verificou-se que, no $2^{\circ}$ semestre de 2018, dos 1.078 professores que poderiam se inscrever para tais editais de fomento à pesquisa, visto atenderem ao requisito básico, qual seja, possuir o título de Doutor em Ciências ou Doutor em Filosofia, apenas 401 se candidataram. Sobre esses dados merecem destaque que 112 daqueles docentes que se candidataram a este edital para bolsas IC, que são as "de entrada" em atividades de pesquisa, não estavam vinculados a nenhum programa de pós-graduação (Quadro 10).

Quadro 10- Perfil da participação docente em edital institucional interno da UFV para bolsas de Iniciação Científica (IC), $2^{\circ}$ semestre de 2018

\begin{tabular}{|c|c|c|c|c|}
\hline Campus & $\begin{array}{c}\text { Centro de } \\
\text { Ciências }\end{array}$ & $\begin{array}{c}\text { Docentes habilitados } \\
\text { para se candidataram } \\
\text { a editais para bolsas IC }\end{array}$ & $\begin{array}{c}\text { Docentes candidatos } \\
\text { ao edital para } \\
\text { bolsas IC } \\
\text { considerando } \\
\text { lotação }\end{array}$ & $\begin{array}{c}\text { Docentes não participantes } \\
\text { de programas e pós- } \\
\text { graduação que se } \\
\text { candidataram ao edital } \\
\text { para bolsas IC }\end{array}$ \\
\hline CRP $^{8}$ & - & 112 & 12 & 9 \\
\hline CAF & - & 78 & 11 & 8 \\
\hline \multirow{2}{*}{ CAV } & CCH & 163 & 50 & 25 \\
\cline { 2 - 5 } & $\mathbf{C C E}$ & 289 & 112 & 39 \\
\cline { 2 - 5 } & $\mathbf{C C B}$ & 246 & 128 & 9 \\
\cline { 2 - 5 } & $\mathbf{C C A}$ & 190 & 88 & \\
\hline
\end{tabular}

${ }^{8}$ Campus Rio Paranaíba; CAF- Campus Florestal; CAV- Campus Viçosa; CCH- Centro de Ciências Humanas, Letras e Artes; CCE- Centro de Ciências Exatas; CCB- Centro de Ciências Biológicas e da Saúde; CCA: Centro de Ciências Agrárias

Revista Brasileira de Pós-graduação-RBPG, ISSN (on-line): 2358-2332.

Brasília, v.16, n. 36, jul./dez., 2020.

Estudos 


\begin{tabular}{|l|l|l|l|}
\hline Totais & $\mathbf{1 . 0 7 8}$ & $\mathbf{4 0 1}$ & 112 \\
\hline
\end{tabular}

Fonte: quadro elaborado pelo autor.

Tanto aqueles que se candidataram, quanto os que optaram por não fazê-lo merecem cuidadosa avaliação e políticas institucionais próprias no intuito de estimular e suportar sua inserção futura em atividades de pesquisa - atividades da carreira docente de nível superior e função constitucional da instituição. $\mathrm{Na}$ avaliação da vinculação a programas de pósgraduação, destaca-se que dentre os docentes doutores desta instituição, 542 estavam credenciados em, pelo menos, um programa, sendo que, dentre estes, 28 estavam vinculados a três programas internos distintos (Dados não demonstrados).

Em relação aos candidatos a bolsas IC no referido edital, verificou-se que, no Centro de Ciências Agrárias, Campus Viçosa, 46\% dos docentes neste centro lotados se candidataram, sendo que $10,2 \%$ destes não constavam como orientadores ou co-orientadores em nenhum dos programas de pós-graduação da UFV. No Centro de Ciências Biológicas e da Saúde, pouco mais da metade (52\%) se candidatou, sendo que $17,2 \%$ destes não participando de nenhum programa de pós-graduação. No Centro de Ciências Exatas, a taxa de docentes habilitados para competirem por tais bolsas foi menor $(38,8 \%)$, com $34,8 \%$ deste grupo de candidatos não orientando ou co-orientando nenhum discente. No Centro de Ciências Humanas, Letras e Artes, verificou-se que menos de 1/3 de seus docentes se candidatou a essas bolsas $(30,7 \%)$, com metade destes sem registro de vinculação a programas em nível de pós-graduação na instituição (Dados não demonstrados).

Resultado a ser interpretado como uma excelente oportunidade institucional, verifica-se ainda que dentre o grupo de docentes apresentando índice h igual a zero, 104 se candidataram para bolsas IC no referido edital. Tal tendência também se mostrou no grupo daqueles com índice $\mathrm{h}$ entre 1 e 4, representando 103 dos docentes da UFV que se inscreveram para este edital (Quadro 11).

Quadro 11 - Número de docentes que se candidataram em edital institucional interno na UFV referente a bolsas de Iniciação Científica (IC), $2^{\circ}$ semestre de 2018, dentre aqueles habilitados para inscrição nestes, considerando diferentes faixas de índice $h$.

\begin{tabular}{|l|l|l|l|l|l|l|}
\hline & \multicolumn{7}{|c|}{ Índice h } \\
\cline { 2 - 7 } & 0 & 1 a 4 & 5 a 9 & 10 a 14 & 15 a 19 & 20 a 44 \\
\hline
\end{tabular}

Revista Brasileira de Pós-graduação-RBPG, ISSN (on-line): 2358-2332.

Brasília, v.16, n. 36, jul./dez., 2020.

Estudos 


\begin{tabular}{|l|c|c|c|c|c|c|}
\hline $\begin{array}{l}\text { Docentes qualificados para } \\
\text { receber bolsa IC }\end{array}$ & 308 & 512 & 243 & 149 & 63 & 29 \\
\hline $\begin{array}{l}\text { Docentes solicitantes de bolsa } \\
\text { IC organizados conforme extrato } \\
\text { de índice h }\end{array}$ & 104 & 103 & 93 & 55 & 32 & 18 \\
\hline
\end{tabular}

Fonte: quadro elaborado pelo autor.

Pelos dados aqui compilados, identifica-se que, dentre as 401 candidaturas neste edital, 207 foram de docentes ainda no início da carreira profissional ou em fase de consolidação de suas atividades de pesquisa e/ou pós-graduação, considerando faixas de índice h nas quais se incluem (entre 0 a 4). Este dado mereceria especial atenção e análise institucional na definição de suas estratégias de crescimento e respectivas políticas a serem desenvolvidas e implementadas em seus campi e distintos centros de ciências. Estas iniciativas devem compreender, em todas as etapas, a avaliação imparcial dos pesquisadores e suas demandas nas diferentes áreas, considerando a pluralidade de todas as áreas de atuação que um pesquisador pode se inserir, a diversidade e peculiaridades de cada área e subárea, bem como o respeito à igualdade, uma vez que todas as áreas e subáreas das ciências são igualmente importantes.

Nesses dados, verifica-se, ainda, que os centros de ciências mais consolidados nas atividades de pesquisa e nos programas de pós-graduação da instituição, em especial, o Centro de Ciências Agrárias e o Centro de Ciências Biológicas e da Saúde, apresentaram um percentual maior de candidatos entre seus docentes. Como citado, vale ressaltar que o Centro de Ciências Agrárias, o centro de pesquisa mais tradicional da UFV, e que possui a maior quantidade de programas de pós-graduação avaliados nos níveis 6 e 7 pela CAPES, apresentou valores inferiores aos do Centro de Ciências Biológicas e da Saúde quanto ao percentual de candidatos no referido edital.

Esses dados merecem avaliação e, se significativos - considerando a mediana da idade dos docentes do Centro de Ciências Agrárias, que é a mais alta de toda a instituição em comparação com as demais unidades acadêmicas, assim como o impacto potencial de eventuais aposentadorias e seu efeito imediato na estrutura acadêmica e de pesquisa da instituição - devem ser adequadamente abordados. Como incentivar a continuidade da excelência científica deste centro, inegavelmente forte alicerce e tradição institucional, uma

\footnotetext{
${ }^{9}$ Iniciação Científica
}

Revista Brasileira de Pós-graduação-RBPG, ISSN (on-line): 2358-2332.

Brasília, v.16, n. 36, jul./dez., 2020.

Estudos 
vez que esta não se transmite ou se transfere por herança aos novos professores, sendo as avaliações dos programas de pós-graduação uma atividade cíclica e permanente? Está aí um grande e premente desafio.

\subsection{Patentes e participação em empresas de inovação tecnológica}

Quanto ao registro de patentes, foi observado um número muito baixo de depósitos obtidos pela UFV no período analisado. Apenas 38 patentes nacionais e oito patentes internacionais foram concedidas, apesar dos 233 pedidos nacionais e 23 internacionais até o ano de 2018. Destaca-se o fato das patentes internacionais até então obtidas pela instituição estarem concentradas em apenas três grupos de pesquisa da instituição. Vale ressaltar que os pedidos internacionais compreenderam repetição do pedido de um mesmo objeto de patente em diferentes países, estando restritas a vacinas recombinantes e peptídeos sintéticos, merecendo destaque que apenas aquelas relacionadas às vacinas derivam de projetos desenvolvidos em parceria com a indústria (Dados não demonstrados).

Com relação aos depósitos de patentes no exterior, os baixos números podem ser, em parte, devidos aos custos diretos envolvidos nos processos de aplicação em diferentes países. Como não existe linha ou fundo adequado para essa atividade no Brasil, é muito difícil para a instituição realizá-la. Em termos de país, quase todas as patentes, principalmente nas áreas mais avançadas da tecnologia, incidem sobre patentes depositadas por instituições estrangeiras (PONTES, 2015). Nesse sentido, este autor afirma que o país não está obtendo retorno dos investimentos em pesquisa, uma vez que, ao contrário, quase todas as pesquisas realizadas são realizadas em instituições públicas, recebendo apoio financeiro público para tal. Essa realidade seria o resultado do modelo implantado, com a realização de pesquisas em instituições públicas, principalmente nas universidades, onde se perde o interesse pela produção científica, por se tratarem de empresas públicas, com seus servidores tendo estabilidade no emprego, seja ele, docente ou técnico-administrativo, com a progressão na carreira alcançada basicamente de acordo com o tempo de serviço. Assim, as decisões dos gestores, dominadas por representantes dos interesses de classe, esgota os recursos que devem ser direcionados à pesquisa, ao ensino e à formação continuada, as quais deveriam ser a finalidade das universidades. 
Com a produção científica fortemente concentrada nas Ciências Agrárias, especialmente Agronomia e suas subáreas, é possível argumentar, quanto aos índices qualitativos, que nesta área os periódicos são de baixo impacto, sendo títulos periféricos e não sendo a produção efetivamente representativa daquela obtida pelos pesquisadores envolvidos, com a priorização do desenvolvimento de cultivares em oposição à publicação de artigos científicos. Pesquisando a quantidade de cultivares protegidas pela UFV no site do Ministério da Agricultura, Pecuária e Desenvolvimento, foram encontradas 40 cultivares de café, canade-açúcar, feijão, milho, pêssego, soja e alface, em parceria com a Embrapa, Epamig, Universidade Federal de Lavras e Fapemig, dentre outros ${ }^{10}$, com oito cultivares ainda em fase de lançamento na respectiva plataforma (Comunicação pessoal. Comissão Permanente de Proteção Intelectual da UFV - CPPD).

Ressalta-se, conforme apontado por Zawislak e Dalmarco (2011), que para o desenvolvimento de inovações, as empresas deveriam estar estabelecendo relações com universidades. As empresas em setores tecnologicamente estáveis parecem incorporar os resultados de alta tecnologia das universidades, impulsionando setores antes aparentemente inertes. Os resultados obtidos por esses autores mostraram que as empresas agrícolas estariam se relacionando tanto com empresas de engenharia - contando principalmente com tecnologias brutas -, quanto com soluções aplicadas. Os relacionamentos de empresas iniciantes estariam baseados principalmente em contatos informais, com patentes não sendo usadas para proteger tecnologias e parecendo não ser a primeira opção na proteção de novas tecnologias. Esses dados merecem ser avaliados, considerando os convênios firmados pela instituição e também no que diz respeito às empresas incubadas vinculadas aos docentes pesquisadores da UFV.

Avaliando quanto à questão da inovação e a aplicação desta, seja em produto ou serviço, considerando-se mais de 15 anos de funcionamento da Incubadora de Empresas de Base Tecnológica, junto ao Centro Tecnológico de Desenvolvimento Regional de Viçosa (CENTEV) da UFV, verificou-se que não mais do que sete de todas as empresas incubadas graduadas até o período avaliado contava em sua estrutura corporativa com um docente da UFV (Dados não demonstrados).

\footnotetext{
${ }^{10}$ Disponível em http://sistemas.agricultura.gov.br/snpc/cultivarweb/cultivares_protegidas.php. Acessado em 17 julho de 2019.
} 
No intuito de conhecer e quantificar o volume de dissertações e teses que permitiram o desenvolvimento de novos produtos, tecnologias e/ou serviços, buscou-se, sem sucesso, esta informação. Conforme destacado por diferentes autores, conhecer como ocorre a transferência tecnológica entre uma IFES com diferentes empresas permite traçar melhores estratégias e políticas institucionais na área, devendo ser estas ações não decorrentes apenas de interesses e ações de cada docente, mas componentes de um ambiente delineado para esta finalidade (PONTES, 2015; ZAWISLAK; DALMARCO, 2011). Neste ponto se encontra algo a ser considerado para estudos específicos quanto à inovação e desenvolvimento tecnológico na instituição.

\subsection{Práticas institucionais de avaliação para progressão funcional e seu comparativo quanto à produção científica indexada de cada docente}

No intuito de compreender o impacto de práticas internas para avaliação docente individual e sua progressão na carreira foram construídas curvas com os valores absolutos referentes à produção científica de cada centro de ciências ou campi entre os anos 2011 a 2016. Desta maneira, foram comparadas as curvas construídas a partir do número total de autorias e coautorias identificadas na base Scopus durante toda a carreira acadêmica de cada docente da UFV versus aquelas obtidas a partir do quantitativo da produção científica individual de cada docente e por este lançada na plataforma interna Radoc/UFV ${ }^{11}$.

A grosso modo, no geral bastante semelhantes morfologicamente, estes gráficos diferem acentuadamente em seus limites superiores no eixo x. Embora o limite da distribuição da produção científica lançada por cada docente na plataforma Radoc seja, em seu extremo superior, próximo a 2.000 produtos, na curva referente aos produtos científicos indexados na base Scopus verificou-se em posicionamento próximo ao valor 550. Destaca-se que estes valores extremos seriam devidos a pouquíssimos docentes, caindo abruptamente para valores menores em ambas as curvas, mas que, no entanto, mantêm semelhante tendência de redução gradativa e proporção na diferença entre seus valores absolutos (Figura 1).

\footnotetext{
${ }^{11}$ Ferramenta interna da UFV destinada a avaliar, em um sistema de pontos, a produção individual com fins de progressão funcional e salarial ao longo da carreira docente.
}

Revista Brasileira de Pós-graduação-RBPG, ISSN (on-line): 2358-2332.

Brasília, v.16, n. 36, jul./dez., 2020.

Estudos 
Figura 1 - (A) Dispersão da produção científica indexada dos docentes da UFV no banco de dados Scopus versus (B) Dispersão da produção científica dos docentes da UFV lançadas no sistema interno Radoc.

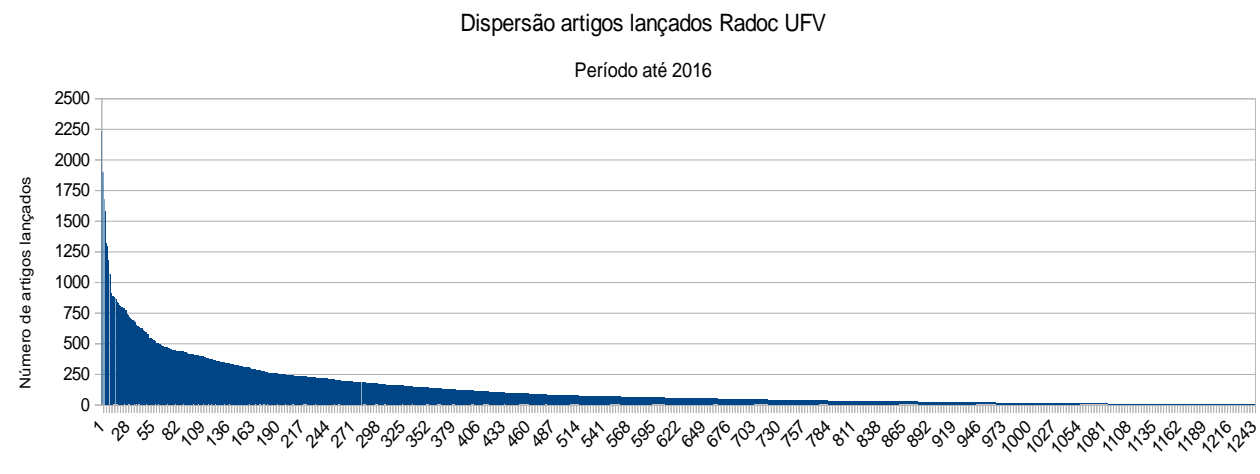

Dispersão artigos UFV indexados na base Scopus

Período até 2016

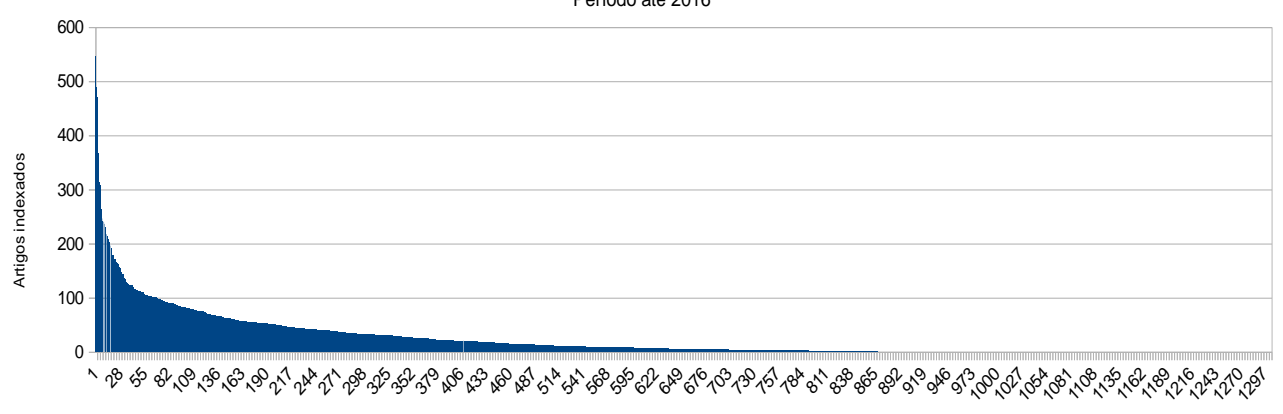

Fonte: Elaborado pelo autor.

Claramente observa-se, ao longo de ambas as curvas, uma proporção aproximada de 1 produto científico indexado para cada 4-5 produtos científicos lançados no sistema de avaliação funcional docente interno Radoc. Tal achado pode indicar certo desprezo ou desconsideração da instituição sobre a produção acadêmica de excelência como requisito para a avaliação e progressão funcional de seus docentes, o que na prática representa uma não valorização da produção científica enquanto esta ter se dado em veículos indexados ou não. Desta maneira, há a aceitação para progressão funcional e, consequentemente, salarial, de "produtos científicos" divulgados em veículos que não geram citações ou sem impacto reconhecido por seus pares, não atendendo a parâmetros qualitativos mínimos praticados e reconhecidos nacional e internacionalmente. $\mathrm{Na}$ soma total, a proporção de produtos científicos não indexados lançados pelos docentes no sistema interno para avaliação 
individual e progressão na carreira, significa algo em torno de 70 a $75 \%$ de todos os produtos distribuídos sem significativa diferenciação por todos os centros e campi (Dados não demonstrados).

Também merece destaque, enquanto análise quantitativa, os valores extremos observados nas curvas semelhantes construídas sob a mesma estratégia para cada centro ou campus. Apesar de haver morfologias similares nas curvas de dispersão referentes aos valores absolutos de produção acadêmica lançada por cada docente no sistema Radoc, os campi em Florestal e Rio Paranaíba e o Centro de Ciências Humanas, Letras e Artes no campus Viçosa apresentaram valores extremos máximos, bem inferiores aos observados nas curvas dos demais centros do campus Viçosa.

Comparativamente, este achado permitiu identificar as diferenças nos volumes da produção entre os diferentes campi e mesmo entre diferentes áreas das ciências no campus Viçosa. Como na análise anterior (Figura 1), apesar de morfologias semelhantes, há valores bastante discrepantes quando se verifica o eixo $\mathrm{x}$, no qual está indicado o quantitativo individual da produção científica de cada docente da UFV.

Nas curvas referentes à produção científica indexada individual de cada docente dos campi em Florestal e Rio Paranaíba, bem como no Centro de Ciências Humanas, Letras e Artes, campus Viçosa, os valores máximos foram significativamente mais baixos do que aqueles observados nos demais centros do campus Viçosa, não raramente apresentando diferenças de valores da ordem de 10 vezes, dentre os valores máximos nos eixos x dos referidos quadros, assim como nas curvas de cada campus ou centro. Em todas estas curvas, independente da unidade administrativa e centro de ciências, a partir dos extremos superiores, passando por uma área que concentra valores médios desta produção, é possível verificar nos extremos quantitativos inferiores destas curvas uma grande concentração de docentes que apresentam produção científica individual indexada igual a zero (Figura 2). Estes dados já foram anteriormente evidenciados neste estudo.

Figura 2 - Curvas de dispersão do quantitativo da produção científica individual dos docentes da $\mathrm{UFV}^{12}$ considerando valores lançados no sistema interno para avaliação e progressão funcional, agrupados conforme campus e/ou centro de ciências.

12 Florestal - Campus de Florestal; Rio Paranaíba - Campus de Rio Paranaíba; CCA - Centro de Ciências Agrárias; CCE - Centro de Ciências Exatas; CCB - Centro de Ciências Biológicas e da Saúde; CCH - Centro de Ciências Humanas, Letras e Artes. 

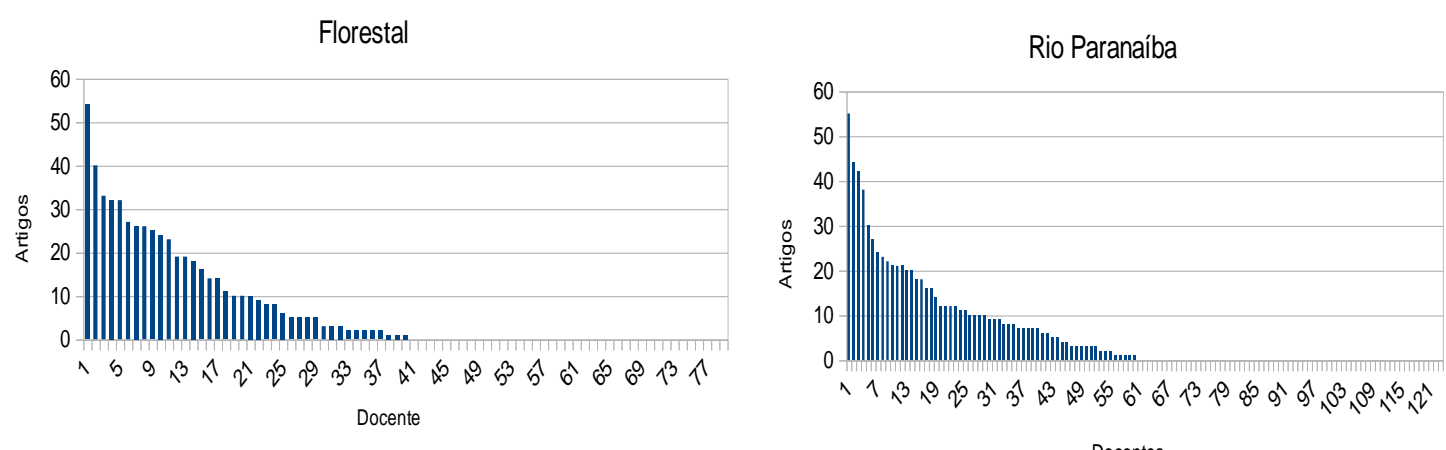

CCA
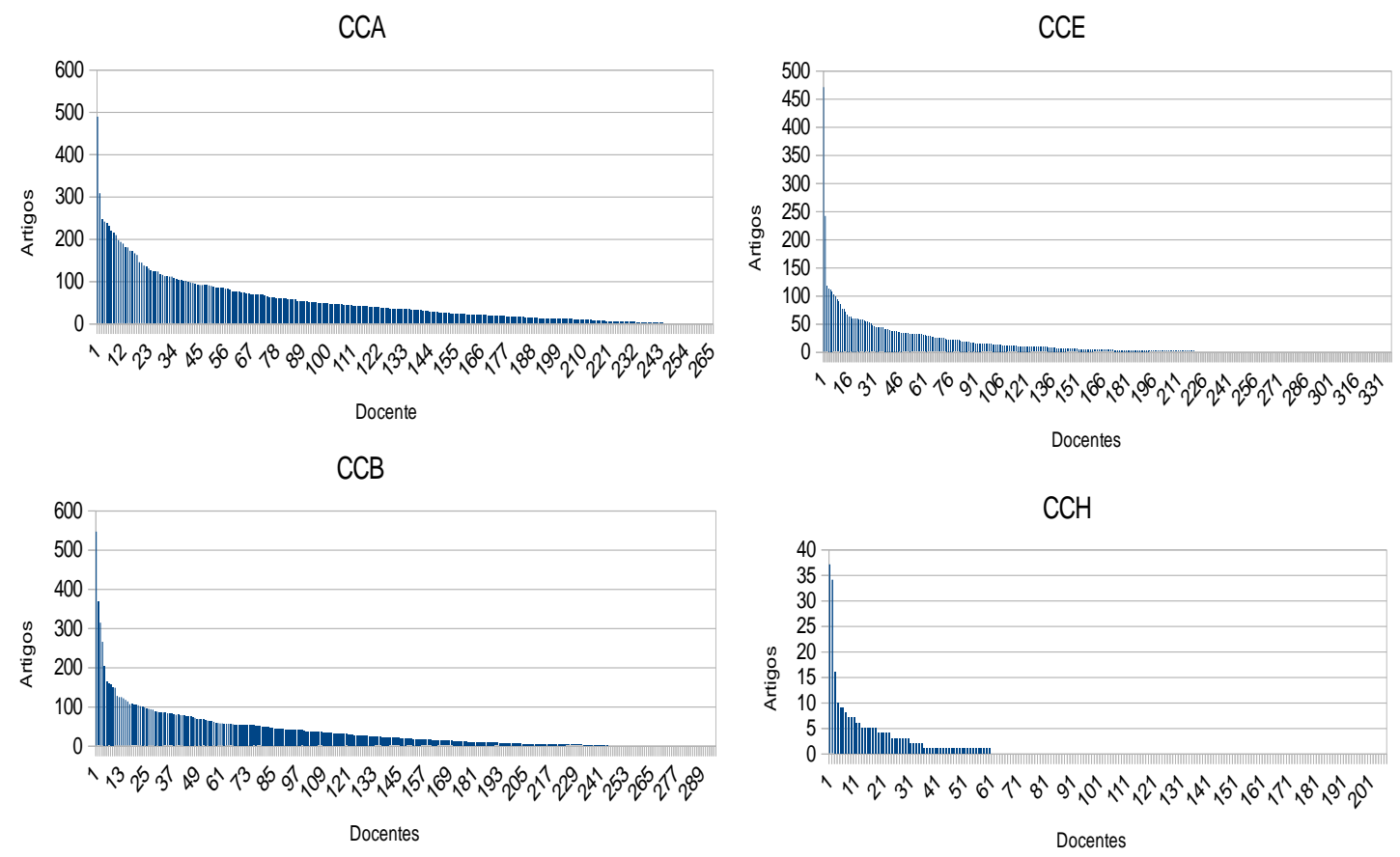

Fonte: gráficos elaborados pelo autor

Estes resultados demonstram tanto a variação no perfil geral dos docentes no que se refere à sua produtividade científica entre os diferentes campi e centros de ciências, quanto à grande variação desta produção individual, mesmo entre cada uma das unidades acadêmicas da UFV. Como destacado em outras partes deste estudo, não sendo os valores entre campi e centros apresentados baseados em dados normalizados, tais resultados merecem criteriosa avaliação institucional no intuito de se entender a razão de valores tão díspares em cada campus e centros de ciências, bem como em cada uma destas unidades. A partir de então, seria possível identificar tanto possíveis gargalos institucionais, quanto excelentes oportunidades, por meio das quais seria possível delinear metas e estratégias específicas. 
Comum a todas as universidades públicas, o princípio da indissociabilidade entre ensino, pesquisa e extensão é uma questão relevante no contexto do sistema universitário brasileiro, estando expresso na Lei de Diretrizes e Bases da Educação Nacional, Lei n. 9394, de 1996; e no artigo 207 da Constituição de 1988, com essa legislação máxima federal orientando as universidades quanto à sua autonomia didático-científica, administrativa e financeira e patrimonial. Disto decorre a existência das diretrizes institucionais de cada IFES, incorrendo a estas a responsabilidade e a liberdade administrativa para decidir como projetálas e livremente aplicá-las para o desenvolvimento e implementação de seus instrumentos internos para a execução de suas atividades acadêmicas e administrativas, inclusive em suas práticas internas de avaliação.

Neste contexto, reavaliar os sistemas institucionais internos para progressão funcional pode vir a permitir a racionalização do uso de recursos humanos e financeiros, bem como a identificação das diferentes realidades vivenciadas por suas distintas estruturas e práticas de pesquisa e produção científica. Assim, seria possível identificar potencialmente os docentes, setores e áreas demandantes de uma política institucional estratégica direcionada a incrementar os níveis de excelência de sua produção científica. Desta maneira, estes procedimentos de identificação dos problemas poderia abarcar, ao mesmo tempo e de maneira equilibrada, específica e individualizada em cada centro de ciências e campus, conforme características, especificidades, limitações e demandas na busca por uma qualidade mínima e razoavelmente distribuída dentre todos seus docentes.

Cumpre observar que toda esta ação deve, obviamente, considerar as especificidades e demandar de normalização para cada área da ciência no intuito de permitir uma avaliação comparativa justa e igualitária entre todas, sem, no entanto, desprezar, como contrapartida, a implementação mandatória de sistemas baseados em parâmetros e métricas reconhecidas para avaliação da produção científica docente individual e sua qualidade. Dessa forma, esse processo de avaliação buscaria considerar, segundo Antunes (2015), o desempenho docente em pesquisa a partir de três etapas fundamentais, desde a produção de conhecimento, passando por sua adequada disseminação e, finalmente, sua aplicação.

Considerando a afirmação de Strehl et al. (2016), segundo os quais o aumento da produção de artigos científicos brasileiros indexados em bases internacionais não foi acompanhado por um aumento equivalente no impacto das publicações, o estabelecimento de 
sistemas de avaliação da produção científica, tanto internos quanto externos às instituições, certamente pode ser muito útil, vindo a auxiliar na racionalização do uso dos limitados recursos disponíveis.

Assim, pelo cenário aqui demonstrado, a avaliação quantitativa e qualitativa da produção científica apresenta-se como de grande importância em uma instituição de ensino e pesquisa de nível superior, podendo vir a permitir a identificação e caracterização, de maneira eficiente, de cada centro e unidade. Esta estratégia deve, como já mencionado, sempre entender os diferentes cenários que são e suas demandas de política estratégicas internas específicas que permitam melhoria dos índices de produção científica conforme parâmetros de qualidade internacionalmente reconhecidos, com o delineamento de novos sistemas internos para progressão na carreira docente e o enfrentamento da realidade competitiva entre diferentes instituições de pesquisa, no Brasil e no mundo.

A princípio, neste quesito, pelos dados aqui demonstrados, destaca-se urgência de tais políticas e ações estratégicas específicas para os campi Florestal e Rio Paranaíba, bem como para o Centro de Ciências Humanas, Letras e Artes no campus Viçosa. É preciso, pois, identificar áreas potenciais de pesquisa de excelência nas quais estes campi, bem como para o Centro de Ciências Humanas, Letras e Artes no campus Viçosa, focando e estruturando políticas e ações estratégicas conforme especificidades de cada área, associando-as a atividades administrativas e operacionais eficazes. Desta maneira, o apoio a grupos, docentes e laboratórios específicos, podendo vir a permitir vislumbrar o estabelecimento equilibrado entre pesquisa e produção científica, já alcançado nos demais centros de ciências da instituição.

\subsection{Perfil dos docentes situados no extrato superior da produção científica institucional da UFV}

Listando, por ordem decrescente, os docentes da UFV quanto ao número de autorias e coautorias nas produções científicas indexadas no banco de dados Scopus até o ano de 2016, foram identificados os 30 pesquisadores mais produtivos, verificando-se dentre estes uma variação entre 147 a 545 produtos ao longo de toda carreira acadêmica (Quadro 12).

Revista Brasileira de Pós-graduação-RBPG, ISSN (on-line): 2358-2332.

Brasília, v.16, n. 36, jul./dez., 2020.

Estudos 
MAFRA, Cláudio

"Perfil da produção científica dos docentes em uma Instituição Federal de Ensino Superior No Brasil”"

Quadro 12 - Perfil dos 30 docentes da UFV com maior número de produções científicas (autorias e coautorias) indexadas, organizados por ordem decrescente, conforme base Scopus até o ano de 2016

\begin{tabular}{|c|c|c|c|c|c|c|c|c|c|}
\hline $\begin{array}{l}\text { Centro } \\
\text { de } \\
\text { Ciência } \\
\text { s } \\
\end{array}$ & $\begin{array}{c}\text { Dpto } \\
13\end{array}$ & $\begin{array}{l}\text { Ingress } \\
\text { o na } \\
\text { UFV }\end{array}$ & $\begin{array}{c}\text { Sex } \\
0\end{array}$ & $\begin{array}{l}\text { Orientaçõe } \\
\text { s } \\
\text { concluídas }\end{array}$ & $\begin{array}{c}\text { Produtos } \\
\text { científico } \\
\text { s no } \\
\text { Radoc }\end{array}$ & $\begin{array}{c}\text { Produtos } \\
\text { científico } \\
\text { s no } \\
\text { Scopus }\end{array}$ & $\begin{array}{c}\text { Citações } \\
\text { identificada } \\
\text { s no Scopus }\end{array}$ & $\begin{array}{c}\text { Índic } \\
\text { e h }\end{array}$ & $\begin{array}{c}\text { Idad } \\
\text { e }\end{array}$ \\
\hline CCB & DDE & 1972 & M & 182 & 825 & 545 & 2.280 & 19 & 68 \\
\hline CCA & DZO & 1989 & $M$ & 278 & 735 & 488 & 4.956 & 28 & 63 \\
\hline CCE & DET & 1980 & $\mathrm{M}$ & 599 & 846 & 470 & 3.567 & 25 & 63 \\
\hline $\mathrm{CCB}$ & DBG & 1997 & M & 144 & 393 & 366 & 1.888 & 19 & 52 \\
\hline $\mathrm{CCB}$ & DBG & 1982 & $M$ & 314 & 574 & 313 & 2.736 & 22 & 59 \\
\hline CCA & $\mathrm{DZO}$ & 2004 & $\mathrm{M}$ & 116 & 405 & 307 & 2.500 & 21 & 44 \\
\hline $\mathrm{CCB}$ & $\mathrm{DDE}$ & 1992 & M & 134 & 326 & 264 & 3.510 & 30 & 51 \\
\hline CCA & DEF & 1996 & $M$ & 162 & 501 & 246 & 1.734 & 23 & 61 \\
\hline CCE & DEQ & ND & M & ND & ND & 241 & 2.298 & 23 & ND \\
\hline CCA & DZO & 1997 & $\mathrm{M}$ & 202 & 320 & 240 & 1.257 & 15 & 68 \\
\hline CCA & $\mathrm{DZO}$ & 1997 & $\mathrm{M}$ & 191 & 306 & 236 & 1.511 & 18 & 65 \\
\hline CCA & DZO & 1996 & M & 120 & 330 & 230 & 2.309 & 21 & 66 \\
\hline CCA & DFT & 1986 & M & 205 & 406 & 217 & 1.044 & 16 & 60 \\
\hline CCA & DFT & 1993 & $M$ & 139 & 464 & 213 & 1.298 & 16 & 67 \\
\hline CCA & DZO & 1992 & M & 128 & 246 & 208 & 1.004 & 14 & 59 \\
\hline CCB & $\mathrm{DDE}$ & 1992 & M & 153 & 393 & 203 & 1.578 & 21 & 59 \\
\hline CCA & DPS & 1994 & $M$ & 183 & 381 & 196 & 2.223 & 22 & 53 \\
\hline CCA & DFP & 2004 & $\mathrm{M}$ & 63 & 253 & 192 & 1.305 & 15 & 44 \\
\hline CCA & DZO & ND & $M$ & ND & ND & 188 & 1.274 & 17 & ND \\
\hline CCA & $\mathrm{DZO}$ & 2005 & $\mathrm{M}$ & 114 & 179 & 179 & 638 & 15 & 41 \\
\hline CCA & DEF & 1992 & M & 200 & 285 & 179 & 956 & 16 & 57 \\
\hline CCA & DZO & 2002 & $\mathrm{~F}$ & 80 & 162 & 171 & 807 & 15 & 52 \\
\hline CCA & DFP & 1993 & $M$ & 85 & 198 & 170 & 2.531 & 15 & 63 \\
\hline CCA & $\mathrm{DZO}$ & ND & $M$ & ND & ND & 165 & 1.707 & 21 & ND \\
\hline $\mathrm{CCB}$ & DNS & 1991 & $\mathrm{~F}$ & 100 & 401 & 164 & 1.317 & 18 & 55 \\
\hline CCA & DFP & 1976 & $M$ & 114 & 350 & 161 & 2.038 & 22 & 67 \\
\hline CCB & DVT & 1989 & M & 49 & 237 & 157 & 1.080 & 15 & 56 \\
\hline CCB & DBV & 1995 & $M$ & 180 & 183 & 155 & 1.535 & 22 & 56 \\
\hline CCB & DVT & ND & $\mathrm{F}$ & ND & ND & 149 & 2.239 & 22 & ND \\
\hline $\mathrm{CCB}$ & DBG & ND & $\mathrm{M}$ & ND & ND & 147 & 1.574 & 20 & ND \\
\hline
\end{tabular}

Fonte: quadro elaborado pelo autor.

\footnotetext{
13 Dpto - Departamento; M- Masculino; F- Feminino; CCA- Centro de Ciências Agrárias; CCE- Centro de Ciências Exatas; CCB- Centro de Ciências Biológicas e da Saúde; DBG- Departamento de Biologia Geral; DBV- Departamento de Biologia Vegetal; DDE- Departamento de Entomologia; DEF- Departamento de Engenharia Florestal; DEQ- Departamento de Química; DET- Departamento de Estatística; DFP- Departamento de Fitopatologia; DFT- Departamento de Fitotecnia; DNS- Departamento de Nutrição e Saúde; DPSDepartamento de Solos; DVT- Departamento de Veterinária; DZO- Departamento de Zootecnia; NDInformação não disponível considerando formato da base de dados utilizada a qual não mantém o dado pesquisado para docentes que não se encontram mais na ativa, seja por aposentadoria, seja por redistribuição, ou simplesmente por não estar disponível na referida base consultada.
}

Revista Brasileira de Pós-graduação-RBPG, ISSN (on-line): 2358-2332.

Brasília, v.16, n. 36, jul./dez., 2020.

Estudos 
Destes docentes, 18 são lotados no Centro de Ciências Agrárias, 10 no Centro de Ciências Biológicas e da Saúde e 2 no Centro de Ciências Exatas, com idades variando, à época do levantamento desta informação específica (2018), entre 44 a 68 anos, sendo 8 destes com 55 anos ou menos. Merece destaque que, em relação ao gênero, apenas três mulheres foram identificadas no referido grupo. Neste grupo, cinco docentes se aposentaram no período 2011 - 2016, sendo a data de admissão daqueles que se mantiveram ativos entre 1972 e 2005. Observou-se como característica comum a todos estes docentes uma forte atividade em programas de pós-graduação, com o número total de orientados e co-orientados ao longo da carreira acadêmica variando entre 49 a 599.

Dentre esses docentes foram identificados 23 como bolsistas de Produtividade em Pesquisa do CNPq, dos quais apenas um é bolsista PQ-2, sendo os outros 19 bolsistas na categoria PQ-1A. Observou-se, ainda, variação do índice h desses docentes entre 14 a 30, não incluindo autocitações. Merece destaque que, em apenas dois casos, o índice h foi alterado acima de $10 \%$ quando da inclusão de autocitações, sendo válido este comentário para os demais resultados descritos a seguir, parecendo indicar não ser esta uma prática usual na UFV (Dados não demonstrados).

Organizando, por ordem decrescente, os docentes quanto ao número de citações recebidas até o ano de 2016, conforme indicado no banco de dados Scopus, foram identificados os 30 com maior número de citações, tendo este número variado dentre estes desde 1.574 até 5.435 citações acumuladas ao longo de toda a carreira acadêmica (Quadro $13)$.

Quadro 13 - Perfil dos 30 docentes da UFV com maior número de citações, organizados por ordem decrescente, acumuladas conforme base Scopus até o ano de 2016.

\begin{tabular}{|c|c|c|c|c|c|c|c|c|c|}
\hline $\begin{array}{c}\text { Centro } \\
\text { de }\end{array}$ & $\begin{array}{c}\text { Dpto } \\
14\end{array}$ & $\begin{array}{c}\text { Ingress } \\
\text { o na }\end{array}$ & $\begin{array}{c}\text { Sex } \\
\mathrm{o}\end{array}$ & $\begin{array}{c}\text { Orientaçõe } \\
\mathrm{s}\end{array}$ & $\begin{array}{c}\text { Produtos } \\
\text { científico }\end{array}$ & $\begin{array}{c}\text { Produtos } \\
\text { científico }\end{array}$ & $\begin{array}{c}\text { Citações } \\
\text { identificada }\end{array}$ & $\begin{array}{c}\text { Índic } \\
\text { e h }\end{array}$ & $\begin{array}{c}\text { Idad } \\
\text { e }\end{array}$ \\
\hline
\end{tabular}

${ }^{14}$ Dpto - Departamento; M - Masculino; F- Feminino; CCA - Centro de Ciências Agrárias; CCE- Centro de Ciências Exatas; CCB- Centro de Ciências Biológicas e da Saúde; DBB- Departamento de Bioquímica e Biologia Molecular; DBG- Departamento de Biologia Geral; DBV- Departamento de Biologia Vegetal; DDE Departamento de Entomologia; DEA - Departamento de Engenharia Agrícola; DEF- Departamento de Engenharia Florestal; DEQ - Departamento de Química; DET - Departamento de Estatística; DFPDepartamento de Fitopatologia; DNS - Departamento de Nutrição e Saúde; DPS - Departamento de Solos; DTA - Departamento de Tecnologia de Alimentos; DVT - Departamento de Veterinária; DZO - Departamento de Zootecnia; ND- Informação não disponível considerando formato da base de dados utilizada a qual não mantém o dado pesquisado para docentes que não se encontram mais na ativa, seja por aposentadoria, seja por redistribuição, ou simplesmente por não estar disponível na referida base consultada. 
MAFRA, Cláudio

"Perfil da produção científica dos docentes em uma Instituição Federal de Ensino Superior No Brasil"

\begin{tabular}{|c|c|c|c|c|c|c|c|c|c|}
\hline $\begin{array}{c}\text { Ciência } \\
\text { s }\end{array}$ & & UFV & & concluídas & $\begin{array}{c}\text { s no } \\
\text { Radoc }\end{array}$ & $\begin{array}{c}\text { s no } \\
\text { Scopus }\end{array}$ & $\begin{array}{l}\text { s base } \\
\text { Scopus }\end{array}$ & & \\
\hline $\mathrm{CCB}$ & DBV & 2010 & $\mathrm{M}$ & 46 & 119 & 123 & 5.435 & 44 & 43 \\
\hline $\mathrm{CCA}$ & $\mathrm{DZO}$ & 1989 & M & 278 & 735 & 488 & 4.956 & 28 & 63 \\
\hline CCE & DEQ & 1994 & M & 101 & 3 & 116 & 4.571 & 24 & 51 \\
\hline CCA & DEA & 1992 & $\mathrm{M}$ & 43 & 133 & 89 & 3.678 & 31 & 52 \\
\hline $\mathrm{CCE}$ & DET & 1980 & $\mathrm{M}$ & 599 & 846 & 470 & 3.567 & 25 & 63 \\
\hline $\mathrm{CCB}$ & DDE & 1992 & $\mathrm{M}$ & 134 & 326 & 264 & 3.510 & 30 & 51 \\
\hline CCB & DBV & 1994 & $\mathrm{M}$ & 86 & 119 & 120 & 2.749 & 29 & 51 \\
\hline $\mathrm{CCB}$ & DBG & 1982 & $\mathrm{M}$ & 314 & 574 & 313 & 2.736 & 22 & 59 \\
\hline CCA & DFP & 1993 & $\mathrm{M}$ & 85 & 198 & 170 & 2.531 & 15 & 62 \\
\hline $\mathrm{CCA}$ & DZO & 2004 & $\mathrm{M}$ & 116 & 405 & 307 & 2.500 & 21 & 44 \\
\hline $\mathrm{CCA}$ & DZO & 1996 & $\mathrm{M}$ & 120 & 330 & 230 & 2.309 & 21 & 66 \\
\hline $\mathrm{CCE}$ & DEQ & ND & $\mathrm{M}$ & ND & ND & 241 & 2.298 & 23 & $\mathrm{ND}$ \\
\hline CCB & DDE & 1972 & $\mathrm{M}$ & 182 & 825 & 545 & 2.280 & 19 & 68 \\
\hline CCB & DVT & ND & $\mathrm{F}$ & ND & ND & 149 & 2.239 & 22 & ND \\
\hline $\mathrm{CCA}$ & DPS & 1994 & $\mathrm{M}$ & 183 & 381 & 196 & 2.223 & 22 & 53 \\
\hline CCB & DBV & 2011 & $\mathrm{M}$ & 36 & 94 & 105 & 2.191 & 27 & 38 \\
\hline CCA & DFP & 1988 & $\mathrm{M}$ & 108 & 62 & 45 & 2.087 & 17 & 56 \\
\hline CCA & DFP & 1976 & $\mathrm{M}$ & 114 & 350 & 161 & 2.038 & 22 & 67 \\
\hline $\mathrm{CCB}$ & DBV & ND & $\mathrm{M}$ & ND & ND & 56 & 1.983 & 20 & ND \\
\hline $\mathrm{CCE}$ & DTA & 1996 & $\mathrm{~F}$ & 90 & 152 & 107 & 1.971 & 24 & 55 \\
\hline $\mathrm{CCA}$ & DFP & 1994 & $\mathrm{M}$ & 98 & 164 & 80 & 1.966 & 22 & 62 \\
\hline CCB & DBB & 1987 & $\mathrm{~F}$ & 108 & 182 & 77 & 1.922 & 24 & 60 \\
\hline CCE & DTA & ND & $\mathrm{M}$ & ND & ND & 53 & 1.916 & 18 & $\mathrm{ND}$ \\
\hline $\mathrm{CCB}$ & DBG & 1997 & $\mathrm{M}$ & 141 & 393 & 366 & 1.888 & 19 & 52 \\
\hline $\mathrm{CCA}$ & DEF & 1996 & $\mathrm{M}$ & 162 & 501 & 246 & 1.734 & 23 & 61 \\
\hline $\mathrm{CCA}$ & DZO & ND & $\mathrm{M}$ & ND & ND & 165 & 1.707 & 21 & ND \\
\hline CCE & DTA & 1987 & $\mathrm{~F}$ & 83 & 237 & 97 & 1.700 & 19 & ND \\
\hline CCB & DDE & 1992 & $\mathrm{M}$ & 153 & 393 & 203 & 1.578 & 21 & 59 \\
\hline $\mathrm{CCB}$ & DNS & 1983 & $\mathrm{~F}$ & 83 & 328 & 116 & 1.577 & 22 & 59 \\
\hline $\mathrm{CCA}$ & DBG & ND & $\mathrm{M}$ & ND & ND & 147 & 1.574 & 20 & ND \\
\hline
\end{tabular}

Fonte: quadro elaborado pelo autor.

Dentre estes docentes, pode ser observada alguma variação com relação ao parâmetro da análise anterior, estando 13 lotados no Centro de Ciências Biológicas e da Saúde, 11 no Centro de Ciências Agrárias e 6 no Centro de Ciências Exatas, com idades variando de 38 a 68 anos, dos quais dez estavam com 55 anos ou menos à época deste levantamento. Quanto ao gênero, apenas 5 mulheres com alta produção foram identificadas nesse grupo. Constatou-se como comum a todos os docentes deste grupo, bem como no grupo anterior, serem muito ativos na pós-graduação, com o número total de alunos de mestrado e doutorado orientados e co-orientados variando entre 36 a 599. Neste grupo de docentes caracterizados como aqueles de maior produção científica indexada na instituição

Revista Brasileira de Pós-graduação-RBPG, ISSN (on-line): 2358-2332.

Brasília, v.16, n. 36, jul./dez., 2020.

Estudos 
avaliada, observou-se a mesma distribuição de bolsas concedidas pelo $\mathrm{CNPq}$ que a demonstrada na análise que deu origem ao Quadro 10, devendo ser destacado que, apesar de mesmo valor, ocorreu alteração na composição entre um quadro e outro. Avaliando o índice h, verificou-se que neste grupo tal métrica variou entre 15 a 44, sem a inclusão de autocitações.

Ao se ranquear por ordem decrescente os docentes da UFV quanto ao índice $h$ acumulado ao longo de toda a vida acadêmica, tomando a produção científica indexada individual no banco de dados Scopus até o ano de 2016, pode-se verificar que, entre os 30 pesquisadores com os índices mais elevados, estes valores variaram de 19 a 44 (Quadro 14).

Quadro 14 - Perfil dos 30 docentes da UFV com maiores valores de índice h, organizados por ordem decrescente, conforme base Scopus até o ano de 2016.

\begin{tabular}{|c|c|c|c|c|c|c|c|c|c|}
\hline $\begin{array}{c}\text { Centro } \\
\text { de } \\
\begin{array}{c}\text { Ciência } \\
\text { s }\end{array}\end{array}$ & $\begin{array}{c}\text { Dpto } \\
15\end{array}$ & $\begin{array}{c}\text { Ingress } \\
\text { o na } \\
\text { UFV }\end{array}$ & $\begin{array}{c}\text { Orientaçõe } \\
\text { s } \\
\text { concluídas }\end{array}$ & $\begin{array}{c}\text { Produtos } \\
\text { científico } \\
\text { s no } \\
\text { Radoc }\end{array}$ & $\begin{array}{c}\text { Produtos } \\
\text { científico } \\
\text { s no } \\
\text { Scopus }\end{array}$ & $\begin{array}{c}\text { Citações } \\
\text { identificada } \\
\text { s no Scopus }\end{array}$ & $\begin{array}{c}\text { Índic } \\
\text { e h }\end{array}$ & $\begin{array}{c}\text { Idad } \\
\text { e }\end{array}$ \\
\hline CCB & DBV & 2010 & M & 46 & 119 & 123 & 5.435 & 44 & 43 \\
\hline CCA & DEA & 1992 & M & 43 & 133 & 89 & 3.678 & 31 & 52 \\
\hline CCB & DDE & 1992 & M & 134 & 326 & 264 & 3.510 & 30 & 51 \\
\hline CCB & DBV & 1994 & M & 86 & 119 & 120 & 2.749 & 29 & 51 \\
\hline CCA & DZO & 1989 & M & 278 & 735 & 488 & 4.956 & 28 & 63 \\
\hline CCB & DBV & 2011 & M & 36 & 94 & 105 & 2.191 & 27 & 38 \\
\hline CCE & DET & 1980 & M & 599 & 846 & 470 & 3.567 & 25 & 63 \\
\hline CCE & DEQ & 1994 & M & 101 & 3 & 116 & 4.571 & 24 & 51 \\
\hline CCE & DTA & 1996 & F & 90 & 152 & 107 & 1.971 & 24 & 55 \\
\hline CCB & DBB & 1997 & F & 108 & 182 & 77 & 1.922 & 24 & 60 \\
\hline CCE & DEQ & ND & M & ND & ND & 241 & 2.298 & 23 & ND \\
\hline CCA & DEF & 1996 & M & 162 & 501 & 246 & 1.734 & 23 & 61 \\
\hline CCB & DBG & 1982 & M & 314 & 574 & 313 & 2.736 & 22 & 59 \\
\hline CCB & DVT & ND & F & ND & ND & 149 & 2239 & 22 & ND \\
\hline CCA & DPS & 1994 & M & 183 & 381 & 196 & 2.223 & 22 & 53 \\
\hline CCA & DFP & 1976 & M & 114 & 350 & 161 & 2.038 & 22 & 67 \\
\hline CCA & DFP & 1994 & M & 98 & 154 & 90 & 1.966 & 22 & 52 \\
\hline CCB & DNS & 1983 & F & 83 & 328 & 116 & 1.577 & 22 & 59 \\
\hline
\end{tabular}

${ }^{15}$ Dpto - Departamento; M- Masculino; F- Feminino; CCA - Centro de Ciências Agrárias; CCE- Centro de Ciências Exatas; CCB- Centro de Ciências Biológicas e da Saúde; DBB- Departamento de Bioquímica e Biologia Molecular; DBG- Departamento de Biologia Geral; DBV - Departamento de Biologia Vegetal; DDE Departamento de Entomologia; DEA - Departamento de Engenharia Agrícola; DEF- Departamento de Engenharia Florestal; DEQ- Departamento de Química; DET - Departamento de Estatística; DFP- Departamento de Fitopatologia; DFT - Departamento de Fitotecnia; DNS - Departamento de Nutrição e Saúde; DPSDepartamento de Solos; DTA - Departamento de Tecnologia de Alimentos; DVT- Departamento de Veterinária; DZO- Departamento de Zootecnia; ND - Informação não disponível considerando formato da base de dados utilizada a qual não mantém o dado pesquisado para docentes que não se encontram mais na ativa, seja por aposentadoria, seja por redistribuição.

Revista Brasileira de Pós-graduação-RBPG, ISSN (on-line): 2358-2332.

Brasília, v.16, n. 36, jul./dez., 2020.

Estudos 


\begin{tabular}{|c|c|c|c|c|c|c|c|c|c|}
\hline $\begin{array}{c}\text { Centro } \\
\text { de } \\
\text { Ciência } \\
\text { s }\end{array}$ & $\begin{array}{c}\text { Dpto } \\
15\end{array}$ & $\begin{array}{c}\text { Ingress } \\
\text { o na } \\
\text { UFV }\end{array}$ & $\begin{array}{c}\text { Orientaçõe } \\
\text { s } \\
\text { concluídas }\end{array}$ & $\begin{array}{c}\text { Produtos } \\
\text { científico } \\
\text { s no } \\
\text { Radoc }\end{array}$ & $\begin{array}{c}\text { Produtos } \\
\text { científico } \\
\text { s no } \\
\text { Scopus }\end{array}$ & $\begin{array}{c}\text { Citações } \\
\text { identificada } \\
\text { s no Scopus }\end{array}$ & $\begin{array}{c}\text { Índic } \\
\text { e h }\end{array}$ & $\begin{array}{c}\text { Idad } \\
\mathrm{e}\end{array}$ \\
\hline CCB & DBV & 1995 & M & 180 & 183 & 155 & 1.535 & 22 & 56 \\
\hline CCA & DZO & 2004 & M & 116 & 405 & 307 & 2.500 & 21 & 44 \\
\hline CCA & DZO & 1996 & M & 120 & 330 & 230 & 2.309 & 21 & 66 \\
\hline CCA & DZO & ND & M & ND & ND & 165 & 1.707 & 21 & ND \\
\hline CCB & DDE & 1992 & M & 153 & 393 & 203 & 1.578 & 21 & 59 \\
\hline CCE & DTA & 1994 & M & 107 & 169 & 110 & 1.283 & 21 & 57 \\
\hline CCB & DBV & ND & M & ND & ND & 56 & 1.983 & 20 & ND \\
\hline CCB & DBG & ND & M & ND & ND & 147 & 1.574 & 20 & ND \\
\hline CCA & DFP & 1991 & M & 107 & 147 & 105 & 1.453 & 20 & 52 \\
\hline CCE & DTA & ND & M & ND & ND & 76 & 1.370 & 20 & ND \\
\hline CCA & DFT & 1992 & F & 86 & 212 & 100 & 532 & 20 & 60 \\
\hline CCB & DDE & 1972 & M & 182 & 825 & 545 & 2.280 & 19 & 68 \\
\hline
\end{tabular}

Fonte: quadro elaborado pelo autor.

Observa-se que a distribuição dos docentes por centro de ciências de lotação foi a mesma daquela verificada quando a análise se deu pelo número de citações, com 11 destes apresentando idade igual ou inferior a 55 anos. Quanto ao sexo, também foi verificado um pequeno número de mulheres, com apenas 5 dentre este seleto grupo docente apresentando os maiores valores do índice $\mathrm{h}$ da instituição. Foi verificado neste grupo que 5 docentes se aposentaram e um foi redistribuído para outra IFES no referido período, com a data de admissão à UFV daqueles que se mantiveram ativos tendo ocorrido entre os anos de 1980 e 2011.

Outrossim, verifica-se considerável alteração na organização e mesmo lotação departamental dos docentes conforme os três parâmetros acima considerados, quais sejam: número total de produções científicas indexadas (Quadro 12), número de citações recebidas (Quadro 13) e índice h (Quadro 14) ao longo da carreira acadêmica, tomando por limite o ano de 2016. No entanto, quando não realizadas estas classificações e mesmo análises comparativas dentre ou entre análises, visto as diferenças diversas entre áreas e subáreas, fica bem evidente, pelos dados complementares adicionados em cada tabela, a história individual e a dedicação dos docentes ali listados. De igual forma, detalhes como diferentes rotinas de publicações e citações em uma área ou outra associação entre data de vinculação à instituição, tempo de contribuição e tempo a complementar para adquirir direito à aposentadoria; e reconhecimento pelos pares, dentre outros parâmetros, merecem análise pormenorizada não 
apenas em nível institucional, mas também em cada departamento e programa e pósgraduação.

Dados como estes, incontestavelmente incômodos e desconfortáveis para muitos, tanto em termos individuais, quanto no coletivo, merecem ser cuidadosa, rotineira e adequadamente monitorados e analisados, pois, conforme destacado por diferentes atores (FREITAS, 1998; TURRI, 2011), deve-se sempre destacar como se dá o conhecimento científico e como está a pesquisa e produção científica em cada instituição e em cada área das ciências, sendo estas questões elementares para um processo pleno de gestão universitária e do conhecimento. Cumpre atentar que todo o processo deve sempre ser conduzido com bastante clareza e transparência, envolvendo outros atores da sociedade, que, sem contestação, é o que mantém e tem o interesse e a necessidade de um sistema de pesquisa, desenvolvimento e inovação atuante e eficiente atendendo aos anseios da Nação.

Já em 1990 Galemberg destacava que, assim como as organizações empresariais e instituições públicas que buscam a avaliação como forma de garantir seu constante desenvolvimento e aprimoramento de suas áreas, atividades e negócios, sem avaliações sistemáticas do ensino e da produção científica não se alcança o progresso científico nas universidades.

\section{CONCLUSÕES}

Como demonstrado, a abordagem aqui apresentada pode ser aplicada ao microcosmo de cada universidade e instituição de pesquisa com potencial de apoiar o desenvolvimento e o crescimento do país pelo uso racional, equilibrado e eficaz dos recursos investidos em pesquisas, projetos de tecnologia e inovação. Apesar do considerável potencial identificador de oportunidades para o conhecimento e crescimento institucional, tais estudos são raros e geralmente não bem considerados e compreendidos pela comunidade interna quando realizados e divulgados.

Como, de acordo com as leis brasileiras, cada IFES é administrada com relativa autonomia, algumas das ações de reestruturação e operação podem e devem ser definidas e implementadas internamente. Com foco nos programas de pós-graduação, um nível de qualidade mais alto a ser exigido quanto aos veículos nos quais se darão as publicações dos produtos de suas dissertações e teses merece atenção, devendo tal conduta ser reavaliada e 
recomendada em seus regimentos internos, considerando especificidades, áreas e extratos de avaliações.

No geral, dentre outras ações, também poderiam ser reavaliados os parâmetros considerados para a contratação de novos docentes, com maior valorização da experiência e produção científica quando do delineamento dos editais e aplicação das provas de seleção. Também, o estabelecimento de metas por áreas, dentro de um contexto de interesse institucional, rediscutindo-se seus sistemas internos para avaliação das carreiras do corpo docente, requisitos para progressão funcional, regime de contratação e licenças sabáticas, sem desconsiderar as diferentes realidades de cada um dos grupos ao qual se destina tal contratação, deveria ser levado em conta.

Todas estas ações têm como intuito a melhoria no perfil da produção científica dos docentes e grupos, considerando a normalização dos índices quantitativos e qualitativos de toda a produção científica, de maneira a permitir a comparação entre as diferentes áreas das ciências, norteando-se por estratégias e interesses institucionais transparentes, bem definidos e não corporativos.

Assim, estimular o início de atividades de pesquisa por aqueles docentes e grupos que ainda não estão nesta prática, bem como reforçar e/ou fazer avançar a excelência daquelas áreas nas quais a instituição já se faz nacional e internacionalmente reconhecida, com, consequente e desejável retorno à sociedade dos investimentos, anseios e expectativas a cada IFES dedicados.

\section{AGRADECIMENTO}

O autor gostaria de expressar uma gratidão especial aos professores Dr. Emerson Medeiros Del Ponte, do Programa de Pós-Graduação em Patologia Vegetal, e Dr. Adriano Nunes Nesi, do Programa de Pós-Graduação em Fisiologia Vegetal, ambos da UFV, por suas análises críticas e metodológicas; à Dra. Ana Louise de Carvalho Fiuza, do Programa de PósGraduação em Economia Rural, UFV, pelo incentivo contínuo ao desenvolvimento e publicação deste estudo; aos Srs. Eduardo Pereira Monteiro e Marco Aurélio Ferreira de Oliveira, secretários do Programa de Pós-Graduação em Bioquímica Aplicada, pelo apoio na coleta de dados referentes aos valores Qualis e Fator de Impacto de cada veículo nos quais se deram as produções científicas indexadas da UFV no período avaliado; aos Srs. Higor Sette 
Pereira e Renato Lima Senra, discentes do Programa de Bioquímica Aplicada da UFV, por seus comentários sobre a estrutura deste manuscrito. $\mathrm{O}$ autor é bolsista de Produtividade em Pesquisa do Conselho Nacional de Desenvolvimento Científico e Tecnológico (CNPq).

\section{REFERÊNCIAS}

ABRAMO, G.; CIRIACO, T. C.; D'ANGELO, A. Should the research performance of scientists be distinguished by gender? Journal of Informetrics, v. 9, n.1, p. 25-38. 2015.

ANDRADE, R. S.; MARTELLI, D. R. B.; SWERTS, M. S. O.; OLIVEIRA, E. A.; MARTELLI JR., H. Scientific production of the Brazilian Council for Scientific and Technological Development (CNPq) researchers in the field of Oral Medicine and Oral Pathology granted with a scientific productivity fellowship. Oral Surgery, Oral Medicine, Oral Pathology and Oral Radiology. Journal of the Brazilian Society of Tropical Medicine, v. 52, 2019.

ANTUNES, A. A. How to evaluate scientific production. Revista do Colégio Brasileiro de Cirurgiões, v. 42, spl. 1, p. 17-19, 2015.

BARATA, R. B. Dez coisas que você deveria saber sobre o Qualis. Revista Brasileira de Pós-Graduação, v. 13, n. 30, 2016. $23,2019$.

Necessary changes in the evaluation of graduate programs in Brazil. Interface, v.

CHOU, O. N. A comparison study of impact factor in Web of Science and Scopus databases for engineering education and educational technology journals. Issues in Informing Science and Information Technology, v. 9, p. 187-194, 2012.

COURAL, J. R.; WILLCOX, L. C. B. Impact factor, scientific production and quality of Brazilian medical journals. Memórias do Instituto Oswaldo Cruz, v. 98, n. 3, p. 293-297, 2003.

DINIZ-FILHO, J. A. F.; FIORAVANTI, M. C. S.; BINI, L. M.; RANGEL, T. F. Drivers of academic performance in a Brazilian university under a government-restructuring program. Journal of Informetrics, v. 14, n. 3, 2016.

FREITAS, M. H. A. Avaliação da produção científica: considerações sobre alguns critérios. Psicologia Escolar e Educacional, v. 2, n. 3, 1998.

GALEMBECK, F. Sem avaliações, sem progresso. Ciência e Cultura, v. 42, n. 9, p. 627-628, 1990.

GÈNOVA, G.; ASTUDILLO, H.; FRAGA, A. The scientometric bubble considered harmful. Science and Engineering Ethics, v. 22, p. 227-235, 2016. 
HIRSCH, J. E. An index to quantify an individual's scientific research output. Proceedings of National Academy of Science of USA, v. 102, n. 46, p. 16569-16572, 2005.

JOSHI, A. Comparison between Scopus and ISI Web of Science. Journal Global Values, v. 8, n. 1, p. 1-11, 2016.

KAMDEM, J. P.; ROOS, D. H.; SANMI, A. A.; CALABRÓ, L.; ABOLAJI, A. O.; OLIVEIRA, C. S.; BARROS, L. M.; DUARTE, A. E.; BARBOSA, N. V.; SOUZA, D. O.; ROCHA, J. B. T. Productivity of CNPq researchers from different fields in biomedical sciences: The need for objective bibliometric parameters - A report from Brazil. Science and Engineering Ethics, v. 25, p. 1037-1055, 2019.

MARTELLI, D. R.; OLIVEIRA, M. C. L.; PINHEIRO, S. V.; SANTOS, M. L.; DIAS, V.; SILVA, A. C. S.; MARTELLI-JÚNIOR, H.; OLIVEIRA, E. A. Profile and scientific output of researchers recipients of CNPq productivity grant in the field of medicine. Revista da Associação Médica Brasileira, v. 65, n. 5, p. 682-690, 2019.

MOSCHKOVICH, M.; ALMEIDA, A. M. F. Desigualdades de gênero na carreira acadêmica no Brasil. Dados, v. 58, n. 3, p. 749-789, 2015.

MOSS-RACUSIN, C.A.; DOVIDIO, J.F.; BRESCOLL, V.L.; GRAHAM, M.J.;

HANDELSMAN, J. Science faculty's subtle gender biases favor male students. Proceedings of the National Academy of Sciences, v. 109, n. 41, p. 16474-16479, 2012.

PERLIN, M. S.; SANTOS, A. A. P.; IMASATO, T.; BORENSTEIN, D.; DA SILVA, S. The Brazilian scientific output published in journals: A study based on a large CV database. Journal of Informetrics, v. 11, n. 1, p. 18-31, 2017.

PICININ, C. T.; PILATTI, L. A.; KOVALESKI, J. L.; GRAEML, A. R.; PEDROSO, B. Comparison of performance of researchers recipients of CNPq productivity grants in the field of Brazilian production engineering. Scientometrics, v. 109, p. 855-870, 2016.

PONTES, P. Brazilian scientific production vs. innovation and technology. Brazilian Journal of Otorhinolaryngology, v. 81, n. 4, p. 343-344, 2015.

SANTOS, L R.; RABELO, D. M. R. S. Produção científica: Avaliação, ferramentas e indicadores de qualidade. Ponto de Acesso, v. 11, n. 2, p. 3-33, 2017.

SILAGHI-DUMITRESCU, R.; SABAU, A. Scientometric analysis of relative performance in a key university in Romania. Scientometrics, v. 99, p. 463-474, 2014.

STREHL, L.; CALABRÓ, L.; SOUZA, D. O.; AMARAL, L. Brazilian science between national and foreign journals: Methodology for analyzing the production and impact in emerging scientific communities. PloS ONE, v. 11, n. 5, 2016. 
TURRI, M. Università in transizione: governança, struttura economica e valutazione. Milano: Guerini e Associati, 2011.

VASCONCELOS, S. M. R.; STENECK, N. H.; ANDERSON, M.; MASUDA, H.; PALACIOS, M.; PINTO, J. C. S., SORENSON, M. The new geography of scientific collaborations. Changing patterns in the geography of science pose ethical challenges for collaborations between established and emerging scientific powers. EMBO Reports, v. 13, p. 404-407, 2012.

ZAINAB, A. N. Personal, academic and departmental correlates of research productivity: a review of literature. Malaysian Journal of Library \& Information Science, v. 4, n. 2, p. 73$110,1999$.

ZAWISLAK, P. A.; DALMARCO, G. The silent run: New issues and outcomes for university-industry relations in Brazil. Journal of Technology Management \& Innovation, v. 6, n. 2, p. 66-82, 2011. 